\title{
Sex-Dependent Regulation of Aromatase-Mediated Synaptic Plasticity in the Basolateral Amygdala
}

\author{
Roland A. Bender, ${ }^{1}$ Lepu Zhou, ${ }^{1}$ Ricardo Vierk, ${ }^{1}$ Nicola Brandt, ${ }^{1}$ Alexander Keller, ${ }^{1}{ }^{-C}$ Christine E. Gee, ${ }^{2}$ \\ ๑Dichael K.E. Schäfer, ${ }^{3}$ and $\mathbb{Q}^{-}$Gabriele M. Rune ${ }^{1}$ \\ ${ }^{1}$ Institute of Neuroanatomy, University Medical Center Hamburg, 20246 Hamburg, Germany, ${ }^{2}$ Institute for Synaptic Physiology, Center of Molecular \\ Neurobiology Hamburg, 20251 Hamburg, Germany, and ${ }^{3}$ Department of Anesthesiology and Research Center Translational Neurosciences, University \\ Medical Center Mainz, 55131 Mainz, Germany
}

The basolateral amygdala (BLA) integrates sensory input from cortical and subcortical regions, a function that requires marked synaptic plasticity. Here we provide evidence that cytochrome $\mathrm{P} 450$ aromatase (AROM), the enzyme converting testosterone to $17 \beta$-estradiol (E2), contributes to the regulation of this plasticity in a sex-specific manner. We show that AROM is expressed in the BLA, particularly in the basolateral nucleus (BL), in male and female rodents. Systemic administration of the AROM inhibitor letrozole reduced spine synapse density in the BL of adult female mice but not in the BL of male mice. Similarly, in organotypic corticoamygdalar slice cultures from immature rats, treatment with letrozole significantly reduced spine synapses in the BL only in cultures derived from females. In addition, letrozole sex-specifically altered synaptic properties in the BL: in acute slices from juvenile (prepubertal) female rats, wash-in of letrozole virtually abolished long-term potentiation (LTP), whereas it did not prevent the generation of LTP in the slices from males. Together, these data indicate that neuron-derived E2 modulates synaptic plasticity in rodent BLA sex-dependently. As protein expression levels of AROM, estrogen and androgen receptors did not differ between males and females and were not sex-specifically altered by letrozole, the findings suggest sex-specific mechanisms of E2 signaling.

Key words: amygdala; androgen; aromatase; estrogen; synaptic plasticity

\section{Significance Statement}

The basolateral amygdala (BLA) is a key structure of the fear circuit. This research reveals a sexually dimorphic regulation of synaptic plasticity in the BLA involving neuronal aromatase, which produces the neurosteroid 17 $\beta$-estradiol (E2). As male and female neurons in rodent BLA responded differently to aromatase inhibition both in vivo and in vitro, our findings suggest that E2 signaling in BLA neurons is regulated sex-dependently, presumably via mechanisms that have been established during sexual determination. These findings could be relevant for the understanding of sex differences in mood disorders and of the side effects of cytochrome P450 aromatase inhibitors, which are frequently used for breast cancer therapy.

\section{Introduction}

It is well known that the roles of estrogens are not limited to the control of reproductive behavior but also include the regulation of a

\footnotetext{
Received May 11, 2016; revised Nov. 11, 2016; accepted Dec. 11, 2016.

Author contributions: R.A.B., C.E.G., and G.M.R. designed research; R.A.B., L.Z., R.V., N.B., and A.K. performed research; M.K.E.S. contributed unpublished reagents/analytic tools; R.A.B., R.V., and N.B. analyzed data; R.A.B. and G.M.R. wrote the paper.

This study was supported by the Deutsche Forschungsgemeinschaft (Grant Ru436/4-1, Ru436/6-1, to G.M.R.; Grant FOR2419, to C.E.G.) and Landesforschungsförderung Hamburg (to C.E.G. and G.M.R.). We thank B. Asmus, B. Holstermann, K. Sander, and C. Schröder-Birkner for their excellent technical support; and Dr. Horst Ehmke (Institute for Cellular and Integrative Physiology, University Hamburg, Medical Center) for permission to perform electrophysiological studies in his laboratory.

The authors declare no competing financial interests.

Correspondence should be addressed to Dr. Gabriele M. Rune, Institute of Neuroanatomy, University Medical Center Hamburg, Martinistrasse 52, 20246 Hamburg, Germany. E-mail: rune@uke.de.

DOI:10.1523/JNEUROSCI.1532-16.2016

Copyright $\odot 2017$ the authors $\quad 0270-6474 / 17 / 371532-14 \$ 15.00 / 0$
}

variety of cognitive functions (Arevalo et al., 2015; Korol and Pisani, 2015). Importantly, estrogens mediating these processes do not necessarily derive from peripheral sources (e.g., ovaries, fat tissue), but can be produced de novo within neurons (Prange-Kiel et al., 2003; Hojo et al., 2004), as cytochrome P450 aromatase (AROM), the final enzyme in $17 \beta$-estradiol (E2) synthesis (converting testosterone to E2) is expressed in the brain, predominantly in the diencephalic and limbic regions (Naftolin and MacLusky, 1982; Roselli and Resko, 1987). Among the regions with high AROM content, the hippocampus is the region that has been most intensely studied (for review, see Hojo et al., 2008; Fester et al., 2011). This high interest has been prompted by clinical observations indicating that women treated with AROM inhibitors for breast cancer experience memory deficits, presumably due to interference with AROM function in the hippocampus (Shilling et al., 2003; Dowsett et al., 2005; Phillips et al., 2011; Bayer et al., 2015). In support of this hypothesis, the impair- 
ment of spine synapse formation and long-term potentiation (LTP), both of which are considered to be key mechanisms of memory formation in hippocampus (Yuste and Bonhoeffer, 2001), were found in rodents after the application of letrozole (Kretz et al., 2004; Grassi et al., 2011; Vierk et al., 2012, 2015), an AROM inhibitor, which promotes AROM phosphorylation and substantially reduces E2 synthesis in hippocampal neurons (Fester et al., 2016). In contrast to other enzymes, the activity of AROM becomes reduced upon phosphorylation by $\mathrm{Ca}^{2+}$-dependent kinases (Balthazart and Ball, 2006; Charlier et al., 2015).

In addition to the hippocampus, the amygdala is a brain region rich in AROM (Balthazart et al., 1991; Sanghera et al., 1991; Shinoda et al., 1994; Wagner and Morrell, 1996; Horvath et al., 1997; Roselli et al., 1998; Zhao et al., 2007). Anatomically, the amygdala comprises approximately a dozen nuclei that are developmentally derived from both pallial and subpallial sources (Swanson and Petrovich, 1998; Puelles et al., 2000; LeDoux, 2007). Functionally, the amygdala is considered a core component of neural circuits that process "emotional" memory, involving the establishment of adequate responses to emotional stimuli such as fear and anxiety (for review, see Pape and Pare, 2010; Tovote et al., 2015). Not surprisingly, alterations in amygdala function are suspected to be causative in neuropsychiatric disorders, such as depression and posttraumatic stress disorder (Pape and Pare, 2010). Interestingly, depression-like symptoms have also been reported by women after treatment with AROM inhibitors (Gallicchio et al., 2012), suggesting that impaired aromatase function in the amygdala may affect synaptic function and underlie these side effects.

Here we examined the consequences of AROM inhibition on synaptic plasticity in the amygdala using in vivo and in vitro approaches. We specifically focused on the basolateral amygdala (BLA), the major sensory input region of the amygdala (OluchaBordonau et al., 2014), which is considered to be a derivative of the cortex (Swanson and Petrovich, 1998). Indeed, the cytoarchitecture and synaptic organization of the BLA resemble those of the neocortex and hippocampus, because projection neurons, comprising $\sim 80 \%$ of the neurons in BLA, are glutamatergic with densely spiny dendrites, whereas local interneurons use GABA as a neurotransmitter (McDonald, 1992; Smith et al., 1998; Kemppainen and Pitkänen, 2000). In addition, neuron types in the BLA exhibit physiological properties that are comparable to those in the hippocampus and neocortex (Pape and Pare, 2010). We recently showed that synaptic plasticity in the hippocampus is regulated by hippocampus-derived E2 in a sex-specific manner, as the inhibition of hippocampal AROM resulted in a robust decrease in spine synapse density and LTP in rodent females but not in rodent males (Vierk et al., 2012). The data presented here suggest that similar mechanisms exist in the BLA, indicating that E2 generated by AROM contributes to a sexually dimorphic regulation of synaptic plasticity in BLA.

\section{Materials and Methods}

\section{Animals}

A total of 54 young adult mice [C57BL/6; postnatal day 56 (P56, breeding stock from Jackson Laboratories, Bar Harbor, ME, USA, RRID:IMSR_JAX: 000664)] were used for these studies. Of these mice, 48 received intraperitoneal injections of either letrozole $(0.4 \mu \mathrm{g} / \mathrm{g}$ body weight $)$ or vehicle $(4 \%$ DMSO in $0.9 \% \mathrm{NaCl}$ ) to determine the effects of in vivo AROM inhibition on synaptic density in BLA and E2 plasma levels. The remaining six mice were used for immunohistochemistry. Further, 48 prepubertal, juvenile rats (Wistar; age, P17-P27, breeding stock from Charles River, Sulzfeld, Germany, RRID:RGD_737929) were used for electrophysiology, immunohistochemistry, electron microscopy, and Western blot analyses, and 156 neonatal rats (Wistar; age, P3) were used for organotypic culture studies.
Animals were housed in the animal facilities of Hamburg and Mainz universities under controlled conditions and had access to food and water ad libitum. All experiments were performed according to legal guidelines and were approved by the institutional committees for the care and use of laboratory animals (University Hamburg, G15-054; University Mainz, G15-1-059).

\section{Organotypic culture}

For preparation of organotypic corticoamygdalar slice cultures, neonatal (P3) rats were decapitated, the brains were removed from the skull and separated at midline, and the hemispheres were sliced coronally (400 $\mu \mathrm{m}$ ) using a tissue chopper (McIlwain). Slices containing amygdala were then preselected, and the dorsal half and the medial third of these slices were removed, leaving mainly amygdalar and ventral cortical structures (with parts of the striatum and hypothalamus) intact. Slices were then placed on moistened translucent membrane inserts $(0.4 \mu \mathrm{m}, 30 \mathrm{~mm}$ in diameter; Millicell-CM Culture Plate Insert, EMD Millipore), which were placed in six-well plates (35 $\mathrm{mm}$ in diameter) and cultivated for up to $14 \mathrm{~d}$ in vitro (DIV) at $37^{\circ} \mathrm{C}$ in a humidified, $\mathrm{CO}_{2}$-enriched atmosphere. From each rat, slices from one hemisphere (usually $3-4$ ) were subjected to experimental manipulation (experimental group), while the corresponding slices from the other hemisphere received vehicle (control group). Culture medium consisted of Neurobasal medium (without phenol red), supplemented with $1 \%$ B27 serum components, $100 \mathrm{U} / \mathrm{ml}$ penicillin/streptomycin (all from ThermoFisher Scientific), and $0.5 \mathrm{~mm}$ L-glutamine (Sigma-Aldrich). The culture medium ( $1 \mathrm{ml} /$ insert) was replaced with fresh medium every second day. After DIV7, the AROM inhibitor letrozole $\left(10^{-7} \mathrm{M} ; 1 \mu \mathrm{l} / \mathrm{ml}\right.$ from a $10^{-4} \mathrm{M}$ stock solution, solved in DMSO; Tocris Bioscience) was added to the medium in the experimental group, whereas the controls received only DMSO $(1 \mu \mathrm{l} / \mathrm{ml}$ medium). At DIV14, the cultures were fixed for immunohistochemistry or electron microscopy, or were harvested for Western blot analyses. A separate set of cultures was used to demonstrate AROM inhibition in vitro (see details below).

\section{Immunohistochemistry}

For immunohistochemistry, young adult mice (P56; three males, three females) and juvenile rats (P20-P24; four males, four females) were deeply anesthetized using a ketamine-xylazine mixture (ketamine 12 $\mathrm{mg} / \mathrm{ml}$, xylazine $0.16 \%$ in saline, i.p.) then transcardially perfused with $4 \%$ paraformaldehyde (PFA) in PBS. Subsequently, the brains were removed from the skull, postfixed for $4 \mathrm{~h}$ in $4 \%$ PFA, cryoprotected with $25 \%$ sucrose (in PBS) for $>48 \mathrm{~h}$, and deep frozen in $-50^{\circ} \mathrm{C}$ isopentane. Frozen brains were cut coronally on a cryotome (HM560, Microm) and sections $(30 \mu \mathrm{m})$ containing amygdala collected in PBS. Selected sections were preincubated "free-floating" with 3\% normal goat serum in PBS plus $0.3 \%$ Triton $\mathrm{X}-100$ for $1 \mathrm{~h}$ at room temperature (RT) followed by primary antibody incubation for $48 \mathrm{~h}$ at $4^{\circ} \mathrm{C}$ in preincubation solution. Two different primary antibodies were applied for AROM detection: a rabbit polyclonal anti-AROM (1:1200; directed against amino acids $488-$ 502 of mouse aromatase; a gift from Dr. I. Azcoitia, Cajal Institute, Madrid, Spain; Yague et al., 2006 [RRID:AB_2631184]) and a mouse monoclonal anti-AROM (1:50; directed against amino acids 376-390 of human aromatase; Acris Antibodies GmbH, Cat\# SM2222P, RRID: AB_973001). Both antibodies revealed similar patterns of immunoreactivity (Bender et al., 2010). However, immunostaining with the rabbit polyclonal anti-AROM was more distinct and was therefore used for most parts of the study. In addition, ER $\alpha$ s and androgen receptors (ARs) were detected using rabbit polyclonal anti-ER $\alpha$ (1:150; HC-20, Santa Cruz Biotechnology) or rabbit polyclonal anti-AR antisera (1:400; N-20, Santa Cruz Biotechnology, Cat\# sc-816, RRID:AB_1563391). Rabbit anti-AROM antibodies were coapplied with mouse monoclonal antibodies directed against parvalbumin (Parv; 1:7000; Swant, Marly, Switzerland, Cat\# 235, RRID:AB_10000343), $\mathrm{Ca}^{2+} /$ calmodulin-dependent protein kinase II (CaMKII; 1:1000; Abcam, Cambridge, UK, Cat\# ab52476, RRID:AB_868641) or glial fibrillary acidic protein (GFAP, 1:700; Sigma-Aldrich, Cat\# G3893, RRID:AB_477010) for doublelabeling studies. After incubation with primary antibodies, the sections were washed twice for $15 \mathrm{~min}$ in PBS before secondary antibodies were applied for $3 \mathrm{~h}$ at RT (for light microscopy: goat 
anti-rabbit IgGs, coupled with biotin, 1:250; Vector Laboratories, Burlingame, CA, USA, Cat\# BA-1000, RRID:AB_2313606; for immunofluorescence: goat anti-rabbit- [Molecular Probes, Cat\# A-11011, RRID:AB_143157] and goat anti-mouse-IgGs [Molecular Probes, Cat\# A-11029, RRID:AB_138404], coupled with Alexa Fluor 568 or Alexa Fluor 488, respectively, 1:500). For light microscopy, sections were then subjected to biotin-avidin-peroxidase complex solution (ABC-Kit, Vector Laboratories, Cat\# PK-7100, RRID:AB_2336827), and antibody binding was visualized by incubating sections in a solution containing $0.04 \%$ diaminobenzidine, $0.01 \% \mathrm{H}_{2} \mathrm{O}_{2}$, and $0.01 \%$ $\mathrm{NiCl}_{2}$. Finally, the sections were mounted on glass slides, dehydrated in a graded ethanol series, and coverslipped with Entellan (Merck). For immunofluorescence, sections were treated for 1 min with $4^{\prime}, 6^{\prime}$ diamidino-2-phenylindole dihydrochloride (DAPI; Sigma, Cat\# D9542), mounted on glass slides, embedded with fluorescent mounting medium (Dako), and coverslipped. Control experiments included treatment of sections as described above but with primary antibodies omitted. No immunoreactivity was observed under these conditions. The results were viewed and photographed using a Leica Axiophot fluorescence microscope.

Corticoamygdalar slice cultures were fixed with $4 \%$ PFA (for $1 \mathrm{~h}$ ) then cryoprotected with $25 \%$ sucrose (in PBS, for $2 \mathrm{~h}$ ), before they were deep frozen on dry ice. For immunohistochemistry, slices were cut on the cryotome $(20 \mu \mathrm{m})$, then sections were mounted on glass slides, dried, and stored at $-20^{\circ} \mathrm{C}$ until further use. The immunodetection procedures were performed as described above (solutions were placed on the slides). Rabbit polyclonal anti-calbindin D28K antibodies (Calb; 1:2000; Merck Millipore, Billerica, MA, USA, Cat\# AB1778, RRID:AB_2068336) were applied for characterization of the cultures.

\section{Electron microscopy}

For electron microscopy, adult mice (P56) were injected intraperitoneally for $7 \mathrm{~d}$ every morning with either letrozole $(0.4 \mu \mathrm{g} / \mathrm{g}$ body weight; letrozole stock: $160 \mu \mathrm{g} / \mathrm{ml} 4 \%$ DMSO in $0.9 \% \mathrm{NaCl}$ ) or with corresponding volumes of $4 \%$ DMSO in $0.9 \% \mathrm{NaCl}$ only $(n=6$, each group and sex). On the final day of treatment, the mice were anesthetized with $\mathrm{CO}_{2}$ and decapitated, the brains were removed from the skull, and the halves were separated and sliced coronally $(400 \mu \mathrm{m})$. Slices containing anterior amygdala were immersed with $2.5 \%$ glutaraldehyde solution (in $0.1 \mathrm{M}$ phosphate buffer) overnight; then the tissue was postfixed with $1 \%$ $\mathrm{OsO}_{4}$, dehydrated in graded ethanol plus propylene oxide and embedded in glycidyl ether (Serva). Blocks were subsequently trimmed to contain predominantly BLA, using the intermediate and external capsules for orientation (Olucha-Bordonau et al., 2014). Semithin sections were cut and stained with toluidine blue to confirm the position of the BLA. Pairs of consecutive serial ultrathin sections were then cut with an ultramicrotome (OmU3, Reichert-Jung) and collected on grids. Sections were stained with uranyl acetate, followed by lead citrate. Electron micrographs were taken at $6600 \times$ magnification (CM100, Philips). Areas occupied by interfering structures, such as large dendrites or blood vessels, were avoided. Organotypic cultures ( $n=15$, females; $n=11$, males) were processed identically. Tissue of age-equivalent rats (P17; $n=4$, each sex) was used for comparison.

\section{E2 detection}

For testing efficacy of AROM inhibition in vivo, young adult mice (P56; $n=6$, each sex and treatment) that had received letrozole or vehicle injections (see above) daily for 6-7 d were decapitated after $\mathrm{CO}_{2}$ anesthesia, and blood was collected from the carotid arteries into Falcon tubes containing $30 \mu \mathrm{l}$ of heparin. To gain blood plasma, tubes were centrifuged at $3500 \mathrm{rpm}$ for $8 \mathrm{~min}$ at $4^{\circ} \mathrm{C}$, and plasma supernatant was then carefully removed. E2 detection was performed by a specialized laboratory (LABOKLIN), using an estradiol-sensitive solid-phase ELISA (EIA 4399, DRG Instruments), preceded by diethylether extraction of E2 from the plasma.

For testing the efficacy of AROM inhibition by letrozole in vitro, a commercially available radioimmunoassay (RIA; E2-RIA-CT KIP0629, DIA Source) was applied. Because the E2 concentration was below the detection limit of the RIA in untreated cultures, we supplemented the culture medium for all cultures with testosterone $\left(10^{-7} \mathrm{M}\right)$ to stimulate
AROM activity. Additionally, the experimental group received letrozole $\left(10^{-7} \mathrm{M}\right)$, and the control group received DMSO $(1 \mu \mathrm{l} / \mathrm{ml})$. The medium was collected every second day for $6 \mathrm{~d}$ (DIV7-13) and subsequently pooled (four inserts, three collections $=12 \mathrm{ml}$ of medium per experimental group and sex in each experiment; $n=1$ ). Media were subsequently loaded under vacuum pressure onto C18 columns (Chromabond $\mathrm{C}_{18 \mathrm{ec}}$, Macherey-Nagel), which had been conditioned with $2 \times 5 \mathrm{ml}$ methanol and equilibrated with $2 \times 5 \mathrm{ml}$ of double-distilled $\mathrm{H}_{2} \mathrm{O}\left(\mathrm{ddd}_{2} \mathrm{O}\right)$. After a wash with $2 \times 6 \mathrm{ml}$ of $\mathrm{ddH}_{2} \mathrm{O}$ to remove hydrophilic compounds, the retained analyte (hydrophobic compound) was eluted $2 \times$ with $500 \mu$ l of methanol. After evaporation of methanol, samples were redissolved in $60 \mu$ of RIA buffer as recommended by the manufacturer. For RIA, $50 \mu \mathrm{l}$ were applied and the original $\mathrm{E} 2$ concentrations were recalculated from the results of these measurements. Four independent experiments ( $n=4$ for each sex and treatment) were performed to gain statistically relevant data.

\section{Western blots}

A group of juvenile rats (P20-P24; eight males, eight females) were anesthetized with $\mathrm{CO}_{2}$ and decapitated; the brains were sliced; and the slices were dissected to isolate the BLA, the central nucleus amygdala (CeA), and the medial amygdala (MeA) using the intermediate and external capsules for orientation. In addition, tissue samples from the somatosensory cortex, the hippocampus, the cerebellum, and, from females, the ovaries were collected. Tissue samples were transferred to plastic tubes and immediately deep frozen in nitrogen. Similarly, from corticoamygdalar slice cultures BLA, MeA, and adjacent cortex were separated and immediately deep frozen in nitrogen. Because protein content was very low in the tissue harvested from a single culture, tissue from 10-12 cultures (deriving from two rats for standard expression analysis or from four rats, if experimental and control groups were compared) was pooled for a Western blot. The extracts were run on 10\% SDS-PAGE under denaturing conditions for analyses. The samples were boiled for $5 \mathrm{~min}$, briefly cooled on ice, and then separated at a voltage that prevented excessive heat. Proteins were blotted on nitrocellulose membranes, the blots were treated with 5\% milk powder in PBS plus $0.3 \%$ Tween 20 and were incubated with primary antibodies overnight at $4^{\circ} \mathrm{C}$. Antibody binding was detected using Immobilon Western Chemiluminescent HRP Substrate (Merck Millipore, Cat\# WBKLS0500). The following primary antibodies were used: mouse monoclonal anti-AROM (1:100; Acris, Cat\# SM2222P, RRID:AB_973001), rabbit polyclonal anti-ER $\alpha$ (1:500; H-20, Santa Cruz Biotechnology, Cat\# sc-543, RRID:AB_631471), rabbit polyclonal anti-AR (1:200; N-20, Santa Cruz Biotechnology, Cat\# sc-816, RRID:AB_1563391), mouse monoclonal anti-GAPDH (1:2000; Ambion, Kassel, Germany, Cat\# AM4300, RRID:AB_437392). With every blot, ovary tissue was run for specificity control.

\section{Electrophysiology}

Amygdala slice preparation. Prepubertal rats (P20-P27) were anesthetized and decapitated, and the brain was removed and immediately transferred into ice-cold artificial CSF (ACSF), which was continuously bubbled with carbogen. Brains were glued and sliced into $400 \mu \mathrm{m}$ serial coronal slices using a microvibratome (VT1000, Leica). Slices containing BLA were transferred to warm $\left(37^{\circ} \mathrm{C}\right)$, continuously oxygenized ACSF [containing the following (in $\mathrm{mM}$ ): $125 \mathrm{NaCl}, 25 \mathrm{NaHCO}_{3}, 2.5 \mathrm{KCl}, 1.25$ $\mathrm{NaH}_{2} \mathrm{PO}_{4}, 2 \mathrm{CaCl}, 1.5 \mathrm{MgCl}_{2}$, and $22.7 \mathrm{D}$-glucose] and allowed to recover at RT for $60 \mathrm{~min}$. Slices were then transferred to a brain slice chamber continuously perfused with oxygenized ACSF $(2-3 \mathrm{ml} / \mathrm{min})$ and maintained for at least $30 \mathrm{~min}$ before recordings at $30 \pm 2^{\circ} \mathrm{C}$.

Extracellular field recording. In all experiments, evoked field EPSPs (fEPSPs) were recorded extracellularly from the basolateral nucleus (BL) while stimulating the lateral nucleus (La) of the amygdala. Borosilicate glass electrodes were filled with ACSF and had resistances between 1.5 and 2.5 $\mathrm{M} \Omega$. Stimulation, data acquisition, and analysis were performed using Pulse software in combination with an EPC-9 patch-clamp amplifier (HEKA Elektronik). The stimulation electrode was positioned in the $\mathrm{La} \sim 200 \mu \mathrm{m}$ from the recording electrode to induce synaptic responses in BL (resistances between 0.5 and $1 \mathrm{M} \Omega$ ). Synaptic responses were preamplified (gain of 10) by a Philips PM 5170 amplifier. Input-output (I/O) relationships were determined by stimulating afferents with in- 

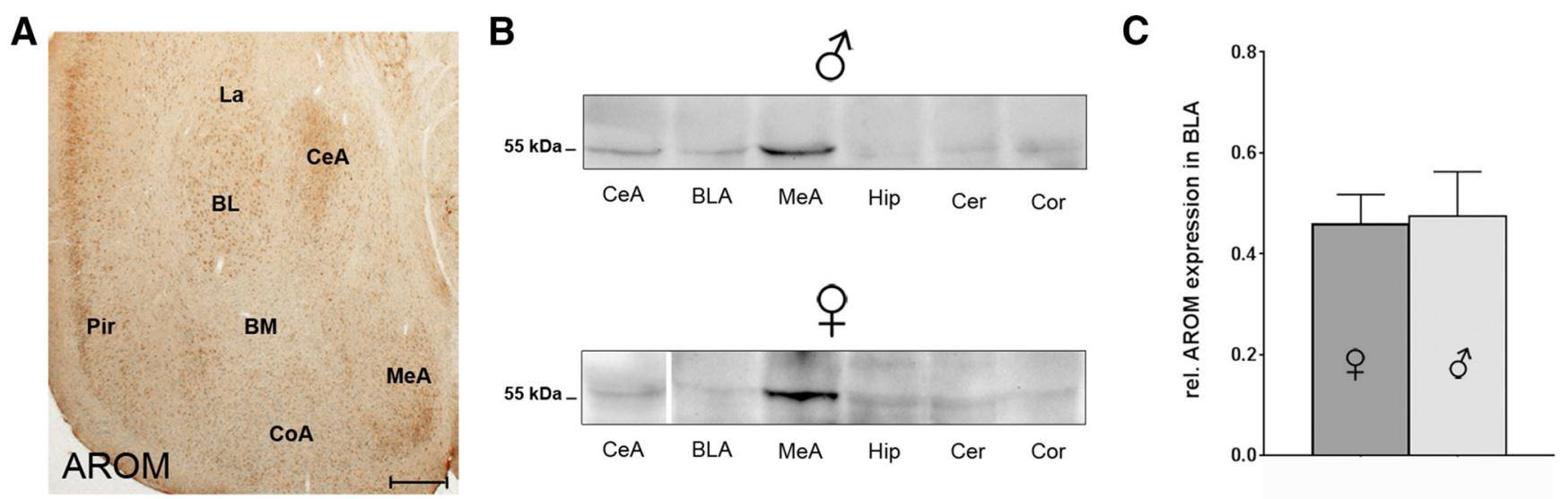

Figure 1. AROM expression in major subregions of rodent amygdala. $A$, Coronal section through anterior amygdala of an young adult mouse, immunostained for AROM using rabbit polyclonal antibodies (Yague et al., 2006). Substantial AROM expression is detectable in the MeA and CeA, in the BL and La nucleus of the BLA, and in the adjacent piriform cortex (Pir). Virtually, no AROM immunoreactivity is seen in the BM of BLA. Low levels of expression were found in the cortical amygdala (COA). Scale bar, $250 \mu \mathrm{m}$. B, Western blots showing AROM protein expression in amygdala subregions (eA, BLA, and MeA of juvenile male and female rats using monoclonal antibodies against AROM (Acris). Tissue from hippocampus (Hip), cerebellum (Cer), and somatosensory cortex (Cor) was blotted for comparison. The strongest signal is found in the MeA. AROM expression levels in the CeA and BLA are comparable to levels in the hippocampus, neocortex, and cerebellum (note: a representative band for the female CeA was inserted from a different gel). C, Quantitative analysis of Western blot data, comparing AROM expression in BLA of age-matched (P20 -P24) juvenile male and female rats. No difference between the sexes was evident (rel. expression of AROM: $0.46 \pm 0.06$ in females; $0.48 \pm 0.09$ in males; $p=0.88 ; n=8$ of each sex).

creasing levels of intensity $(200 \mu$ s monophasic pulses, ranging from 10 to $100 \mu \mathrm{A}$ ) while recording fEPSPs in the BL. In all recordings, single pulses $(0.2 \mathrm{~ms}$, every $2.5 \mathrm{~s})$ were used to adjust the stimulus intensity to evoke synaptic responses that are $<50 \%$ of maximum amplitude and then were applied continuously at $0.05 \mathrm{~Hz}$ throughout every experiment. Data were collected, and three time points were averaged for every minute of recording. In the control experiments, slices were subjected to high-frequency stimulation (HFS) after a $20 \mathrm{~min}$ baseline recording by applying pulses of $0.2 \mathrm{~ms}$ duration at $100 \mathrm{~Hz}$ for $1 \mathrm{~s}$, which were repeated five times with $30 \mathrm{~s}$ intervals. HFS-induced synaptic potentiation in BL was monitored continuously for $70 \mathrm{~min}$ after stimulation. The I/O relationship was obtained before and after HFS. To examine the effects of AROM inhibition, slices were continuously perfused with ACSF containing letrozole $\left(10^{-6} \mathrm{M}\right)$ for $60 \mathrm{~min}$ before HFS. Letrozole treatment was continued until the end of the experiment. The I/O relationships were obtained before letrozole wash-in, $60 \mathrm{~min}$ after wash-in onset (i.e., immediately before HFS) and 70 min after HFS. All mean percentage changes of fEPSP slopes (calculated at $60-70 \mathrm{~min}$ post-HFS) were used as the measure for synaptic potentiation.

\section{Quantitative analyses}

Electrophysiology. Electrophysiology data (non-normalized fEPSP slopes) were computed using PulseFit 8.11 (HEKA Elektronik), SigmaPlot (SPSS), Excel (Microsoft), and SPSS version 18.0 (IBM). All data reported are expressed as the mean \pm SEM. $N$ indicates the number of animals used, and $n$ indicates the number of recorded slices. LTP data were statistically analyzed with a repeated-measures mixed-factor ANOVA using sex as the betweensubject factor and the fEPSP slope as the within-subject factor, testing for differences in the slopes of (1) before and after HFS under control conditions; and (2) before letrozole wash-in, $60 \mathrm{~min}$ after letrozole wash-in onset, and $60 \mathrm{~min}$ after HFS under letrozole. Because the dataset of (1) did not show homogeneity of variances, a Brown-Forsythe test was applied to corroborate data. We further applied a one-way ANOVA to specifically compare the effect of letrozole after HFS between the sexes (2) because this difference is not properly reflected with mixed-factor ANOVA.

Cell counts. To estimate the proportions of AROM-expressing neurons, areas in BL or La were randomly selected in two representative, AROMimmunostained sections of prepubertal rats (P20-P24; $n=4$, each sex). Photographs were taken at $400 \times$ magnification, and the proportion of AROM-immunopositive somata relative to DAPI-positive nuclei (diameter, $>5 \mu \mathrm{m}$ ) was determined in these photographs. Data were averaged to get one representative value (percentage of AROM-positive neurons) per rat and statistically analyzed with the Mann-Whitney $U$ test.
Western blots. Densitometric analysis of band intensities was performed using NIH ImageJ software. For quantification, only bands running on the same gel were analyzed and compared, using GAPDH as a loading control (note that data presented as "rel. expression" have arbitrary units). Different exposure times for AROM (30 min), AR (2-4 $\mathrm{min}), \mathrm{ER} \alpha(3-8 \mathrm{~min})$, and GAPDH (1 $\mathrm{min})$ were required to receive analyzable signals. Data were statistically analyzed using Student's unpaired $t$ tests if two experimental groups were compared (letrozole vs vehicle, male vs female) and ANOVA with Bonferroni's multiplecomparisons test if three sets of data were analyzed ( $\mathrm{ER} \alpha$ and AR expression in BLA vs MeA and CeA).

Electron microscopy. To obtain a comparable measure of synaptic numbers, unbiased for possible changes in synaptic size, the dissector technique was used (Sterio, 1984). The density of spine synapses was calculated with the aid of a reference grid superimposed on the EM prints. Spine synapses were defined as synapses with a clearly recognizable postsynaptic density (i.e., excitatory synapses) on dendritic protrusions. Synapses on dendritic shafts were excluded. Only those spine synapses were counted that were present on the reference section, but not on the lookup section. The dissector volume was calculated by multiplying the unit area of the reference by the distance $(0.09 \mu \mathrm{m})$ between the reference and the look-up section. At least 20 neuropil fields were analyzed per tissue sample, and data were averaged. Statistical analysis was performed using Student's unpaired $t$ test.

Data presentation. All data are presented as the mean \pm SEM. A $p$ value of $<0.05$ was considered to be significant. Prism software (GraphPad, San Diego, CA, USA, RRID:SCR_002798) and G-Power (University Düsseldorf, Düsseldorf, Germany) were used for statistical analyses.

\section{Results}

\section{Substantial expression of AROM in rodent basolateral and} central amygdala

To map its localization in the amygdala, we first determined AROM expression in three major subregions of rodent amygdala, as follows: the MeA, CeA, and BLA [comprising La, BL, and basomedial nuclei (BM)] using immunohistochemistry (Fig. $1 A$ ) and Western blot (Fig. $1 B, C$ ) analyses. Both young adult mice and juvenile rats were used for these studies to establish the basis for subsequent morphological and physiological analyses (see below). As expected, we found robust AROM expression in the MeA (Wagner and Morrell, 1996; Roselli et al., 1998; Zhao et al., 2007), but BLA and CeA 


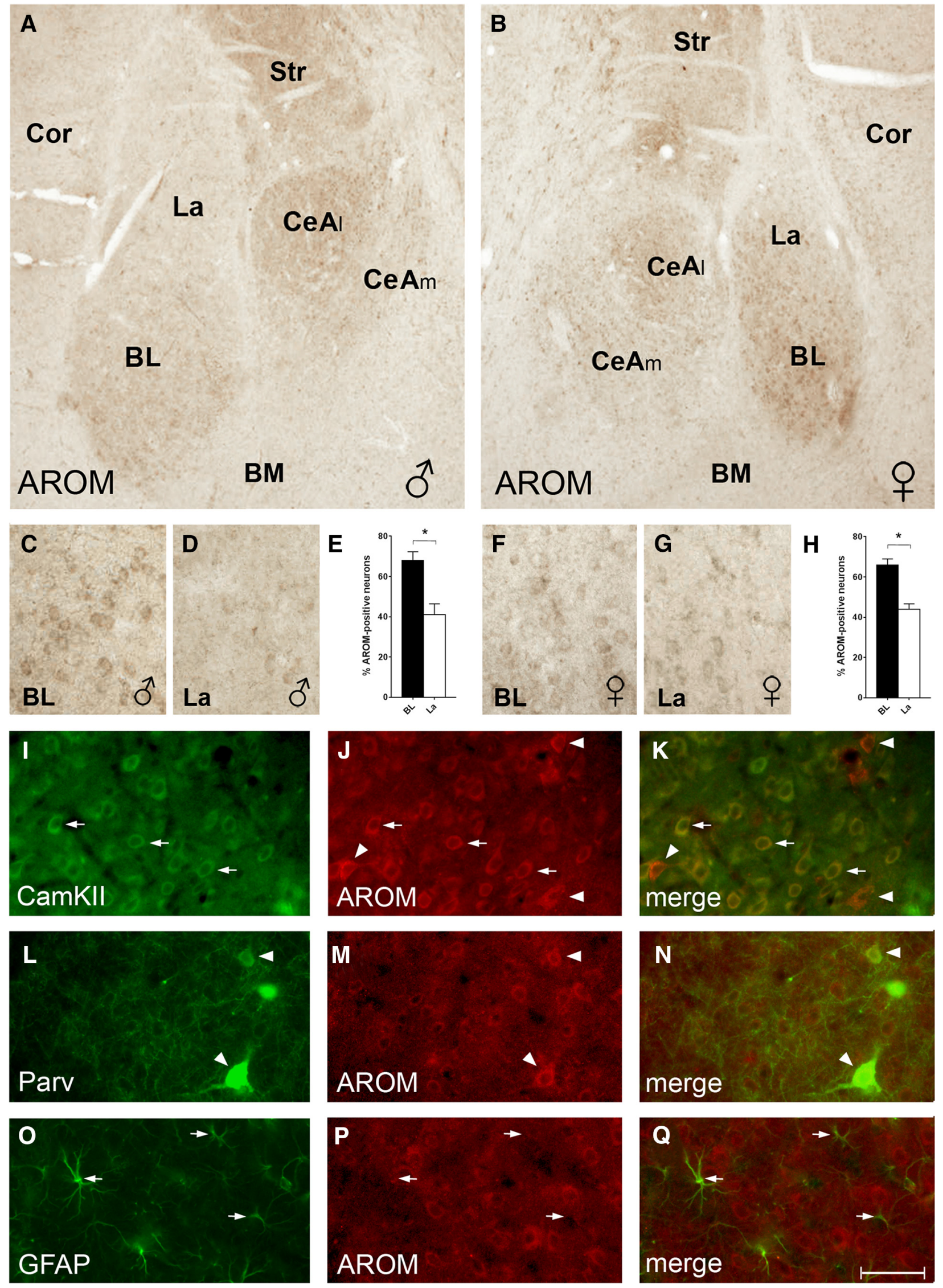

Figure 2. AROM expression in rat BLA and CeA. $\boldsymbol{A}, \boldsymbol{B}$, AROM immunostaining of sections from a juvenile male $(\boldsymbol{A})$ and female $(\boldsymbol{B})$ rat reveals particularly robust AROM expression in subdivisions of the BLA and CeA: in the BLA, the BL had a higher density of AROM-expressing cells compared with the La and BM. In the CeA, the CeAl was more intensely labeled than the CeAm. $\mathbf{C}-\boldsymbol{H}$, Higher-magnification views of the sections shown in $\boldsymbol{A}(\boldsymbol{C}, \boldsymbol{D})$ and $\boldsymbol{B}(\boldsymbol{F}, \boldsymbol{G})$ demonstrate that within BLA the density of AROM-expressing cells is highest in BL, (Figure legend continues.) 
also expressed AROM substantially. Interestingly, in CeA, the lateral subnucleus (CeAl), but not the medial subnucleus (CeAm) showed intense AROM immunoreactivity (Fig. $2 A, B$ ). In the BLA, the AROM signal was observed throughout its anterior-posterior extension, without obvious differences in anterior and posterior subdivisions (Olucha-Bordonau et al., 2014). However, more neurons in the BL compared with the La expressed AROM both in male (68 \pm $4 \%$ in BL vs $41 \pm 5 \%$ in La; $p=0.02 ; n=4$; Fig. $2 C-E$ ) and female juvenile rats $(66 \pm 3 \%$ vs $44 \pm 3 \%$; $p=0.02 ; n=4$; Fig. $2 F-H$ ), whereas virtually no AROM immunoreactivity was found in the BM (Fig. 2A-H). Notably, no differences were evident, when the proportions of AROM-expressing neurons in BL and La were compared between males and females ( $p=0.97$ and 0.6 for BL and La, respectively; $n=4$ each sex; Fig. $2 E, H$ ). Similarly, no difference between the sexes was evident when AROM protein expression in male and female BLA of juvenile rats was determined (rel. expression of AROM: $0.46 \pm 0.06$ in females; $0.48 \pm 0.09$ in males; $p=0.88 ; n=8$; Fig. 1C).

To further characterize the AROM-expressing cells in the BL, sections from juvenile rats were costained with markers for glutamatergic projection neurons (CaMKII; McDonald et al., 2002), certain GABAergic interneurons (Parv) or astrocytes (GFAP). This revealed that CaMKII-immunopositive neurons frequently coexpressed AROM (Fig. $2 I-K$, arrows), but not all AROMpositive cells also expressed CaMKII (Fig. $2 I-K$, arrowheads), indicating that other neuron populations express AROM as well. Indeed, AROM was frequently found to colocalize with the interneuron marker parvalbumin (Fig. $2 L-N$ ), whereas no expression, or only low expression, was seen in astrocytes (Fig. 2O-Q).

\section{AROM inhibition reduces spine synapse density in adult mouse BL sex-specifically}

In the hippocampus, $\mathrm{AROM}$ activity was shown to modulate spine synapse density (Kretz et al., 2004; Hojo et al., 2008; Bender et al., 2010; Zhou et al., 2010), and because BLA is also considered a "cortical" structure (Swanson and Petrovich, 1998), we reasoned that the enzyme might here play a similar role. As virtually identical patterns of AROM expression were observed in rats (Fig. $2 A, B$ ) and mice (Figs. $1 A, 3 A, B$ ), we used mice that had been systemically injected for $7 \mathrm{~d}$ (once daily) with the AROM inhibitor letrozole $(0.4 \mu \mathrm{g} / \mathrm{g}$ body weight $)$ to examine this hypothesis, focusing specifically on BL. Indeed, spine synapse density was altered in BL after letrozole treatment. However, the effects were markedly discrepant between male and female mice; whereas, spine synapse density was reduced in the females by $>50 \%$ (vehicle, $9.2 \pm 0.6$ synapses $/ 10 \mu \mathrm{m}^{3}$; letrozole, $4.2 \pm 0.4$; $p<0.001 ; n=6$; Fig. $3 C-E)$, no reduction was observed in the males (vehicle, $5.6 \pm 0.3$; letrozole, $7.3 \pm 1.4 ; p=0.23$; $n=6$; Fig.

\section{$\leftarrow$}

(Figure legend continued.) in which $68 \pm 4 \%(\boldsymbol{E}$; males, $n=4)$ and $66 \pm 3 \%$ ( $\boldsymbol{H}$; females, $n=4$ ) of presumed neurons (nuclei $>5 \mu \mathrm{m}$ ) were immunoreactive for AROM. Density was significantly lower in La compared with BL both in males and females ( $41 \pm 5 \%$ and $44 \pm 3 \%$, respectively; $p=0.02$ for each sex). However, no significant differences were evident when densities between males and females were compared ( $p=0.7$ and $p=0.6$, respectively, for BL and La). I-K, Coimmunostaining of AROM (red) and CaMKII (green) indicates that AROM expression is frequent in CaMKII-positive projection neurons in the $\mathrm{BL}$ (arrows). However, the presence of strongly AROM-immunoreactive neurons without CaMKII signal (arrowheads) suggests AROM expression also in interneurons. $\boldsymbol{L}-\boldsymbol{N}$, These interneurons include the Parvexpressing subpopulation, as Parv frequently colocalizes with AROM (arrowheads). $\mathbf{0}-\mathbf{Q}$, In contrast, no or only low levels of AROM signal were found in GFAP-immunopositive astroglial cells (arrows). Cor, Cortex; Str, striatum. Scale bar (in Q): $\boldsymbol{A}, \boldsymbol{B}, 200 \mu \mathrm{m} ; \mathbf{C}-\mathbf{G}, 50 \mu \mathrm{m} ; \mathbf{I}-\mathbf{Q}, 25$ $\mu \mathrm{m}$.
3C). Notably, in the BL of male mice, spine synapse density was, under control conditions, already at the level of letrozole-treated females, and letrozole treatment did not cause a further reduction (Fig. 3C). As these discrepancies could have resulted from sexspecific effects of letrozole on E2 synthesis, we measured the plasma E2 concentration after letrozole treatment in a subset of male and female mice. However, while these studies suggest that letrozole may have reduced E2 synthesis of 30\% (vehicle, $3.3 \pm$ $0.4 \mathrm{pg} / \mathrm{ml}$; letrozole, $2.3 \pm 0.4 \mathrm{pg} / \mathrm{ml} ; p=0.09 ; n=12$, in each treatment, if both sexes are considered; Fig. $3 F$, left bars), no difference between the sexes in the response to letrozole was evident (Fig. 3F, middle and right bars), which we expected since the cyclicity of females was not considered in this experimental setup.

\section{Organotypic slice cultures as a tool for the study of amygdala function in vitro}

These in vivo data suggest a sex-specific regulation of synapse densities in BL that involves AROM. However, because systemic application of letrozole does not permit a clear distinction of effects resulting from peripheral (e.g., ovaries, bone, fat tissue) or local (i.e., amygdalar) AROM inhibition, pinpointing the observed sex-specific effect to AROM within BL is not feasible. Further, the potential effects of the female estrous cycle (Woolley and McEwen, 1992) render a comparison of AROM inhibition in adult males and females in vivo difficult, as the content of E2 in female brain tissue varies with the estrous cycle (Kato et al., 2013) and is regulated by gonadotropin-releasing hormone (PrangeKiel et al., 2008). In contrast, in organotypic hippocampal cultures of male and female rats, E2 synthesis did not differ (Fester et al., 2011). Therefore, we decided to establish organotypic cultures of rat amygdala as a tool to study AROM functions in the amygdala more specifically. Because cultures did not survive for an extended period if amygdala alone was cultivated, slice cultures with adjacent cortex (piriform, perirhinal) and parts of the striatum and hypothalamus were used (Fig. 4A).

These "corticoamygdalar" cultures were viable for $>2$ weeks in vitro and reproduced aspects of amygdalar differentiation, such as the expression pattern of the $\mathrm{Ca}^{2+}$-binding protein calbindin D28K (Fig. 4E, F, I,J). As remnants of the external and intermediate capsules were detectable in a substantial proportion of cultures $(\sim 40 \%)$ even after 2 weeks in vitro (Fig. $4 A, G, K$ ), identification of the BLA was feasible, rendering it accessible for Western blot and morphological analyses. Importantly, AROM was expressed in the BLA in vitro (Fig. $4 B, C, O$ ) and was functional, as the conversion of supplemented testosterone to E2 was inhibited by letrozole (Fig. 4D).

\section{AROM inhibition reduces spine synapse density in rat BLA sex-specifically in vitro}

Corticoamygdalar slice cultures were thus used to study the effects of letrozole-mediated AROM inhibition on spine synapse density in the BL in vitro. Generally, this density was only $~ 30 \%$ of the density observed in age-equivalent (P17) rats (Fig. 4, compare $M, N)$, a phenomenon not unknown from culture systems (Drakew et al., 1999) and likely reflecting lesser innervation of BL neurons by cortical afferents or the delayed maturation of intrinsic connectivity under culture conditions. Regardless of the lower synapse density, letrozole effects in vitro were comparable to those in vivo: letrozole treatment reduced spine synapse density in the BL only, if the tissue was derived from females (vehicle, $3.1 \pm 0.2$ synapses $/ 10 \mu \mathrm{m}^{3}$; letrozole, $2.4 \pm 0.2 ; p=0.02 ; n=$ 15 ), but not if it originated from male rats (vehicle, $2.4 \pm 0.2$; 

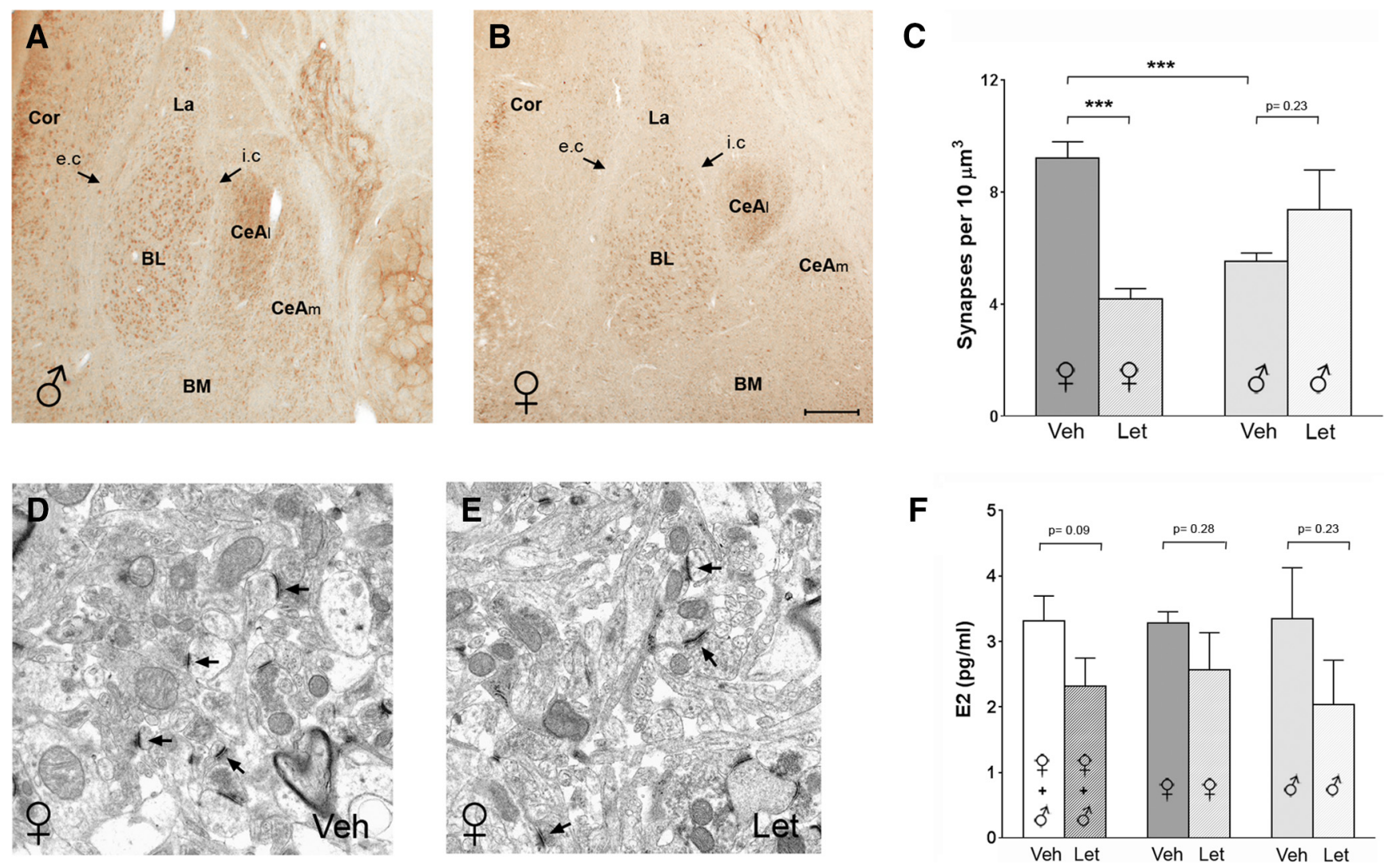

Figure 3. Reduced spine synapse density in $B L$ in adult mice after letrozole treatment. $A, B$, Coronal sections through anterior amygdala of a young adult male $(\boldsymbol{A})$ and female $(\boldsymbol{B})$ mouse show that, as in the juvenile rats, AROM expression is more robust in the BL than in the La, whereas it is virtually absent in the BM. Similarly, the CeAl but not the CeAm of the central amygdala is intensely AROM immunoreactive. Arrows denote the external capsule (e.c.) and intermediate capsule (i.c.).C, Quantitative analysis of spine synapses after vehicle (Veh) or letrozole (Let) treatment, comparing males and females: letrozole caused a significant reduction of spine synapse density in the female mice (Veh, $9.2 \pm 0.6$ synapses $/ 10 \mu \mathrm{m}^{3} ;$ Let, $4.2 \pm 0.4$ synapses $/ 10 \mu \mathrm{m}^{3} ; p<0.001 ; n=6$ each treatment), but not in the males (Veh, $5.6 \pm 0.3$ synapses $/ 10 \mu \mathrm{m}^{3}$; Let, $7.4 \pm 1.4$ synapses $/ 10 \mu \mathrm{m}^{3} ; p=0.22 ; n=6$ each treatment). Notably, in the males, spine synapse density was already, under control conditions significantly lower than in the females $(p<0.001) . \boldsymbol{D}, \boldsymbol{E}$, Representative electron micrographs from the BL of a Veh-treated $(\boldsymbol{D})$ and a Let-treated $(\boldsymbol{E})$ female mouse. Note that spine synapses are present in both, but density is lower in the sections from the mouse treated with letrozole. $F$, Measurement of 22 plasma concentration after daily intraperitoneal injections of letrozole or vehicle in young adult male and female mice ( $n=6$, each sex and treatment) for $7 \mathrm{~d}$ suggest that letrozole reduces peripheral E2 concentration, but the difference did not reach significance ( $p=0.09, n=12$ each treatment, if both sexes are considered; left bars). No difference in the response to letrozole was evident, when males and females were compared. (middle and right bars). Cor, Cortex. Scale bar (in $\boldsymbol{B}): \boldsymbol{A}, \boldsymbol{B}, 200 \mu \mathrm{m} ; \boldsymbol{D}, \boldsymbol{E}, 1 \mu \mathrm{m}$.

letrozole, $2.1 \pm 0.2 ; p=0.14 ; n=11 ;$ Fig. $4 N)$, suggesting that the mechanisms underlying the sex-dependent regulation of spine synapses by $\mathrm{E} 2$ are preserved in vitro. Notably, as in young adult mice (Fig. 3C), spine synapse density was lower in cultures derived from males compared with those derived from females, already under control conditions ( $p=0.03$; Fig. $4 N)$. This effect was not fully mimicked in the age-equivalent juvenile rats, in which the difference between males and females was not significant (females, $9.5 \pm 0.9$; males, $8.4 \pm 1.2 ; n=4$ of both sexes; $p=0.4$; Fig. $4 M)$.

As the observed sex-specific effects could also be a consequence of sex-specific expression changes of either AROM or sex hormone receptors under the influence of letrozole, we further examined whether the $7 \mathrm{~d}$ letrozole treatment had altered the protein expression of AROM, ER $\alpha$ s, or ARs in BLA in vitro. Notably, in addition to AROM (Fig. 4B, C,O), substantial levels of ER $\alpha$ s (Fig. 4P) and ARs (Fig. 4Q) were expressed in the BLA in cultures from both males and females, and no significant differences between the sexes were evident under control conditions (rel. expression of ER $\alpha$ : female, $0.66 \pm 0.10$; male, $0.51 \pm 0.09$; $p=0.33 ; n=7$ of each sex; rel. expression of AR: female, $0.41 \pm$ 0.05 ; male, $0.54 \pm 0.09 ; p=0.11 ; n=8$ of each sex). In addition, letrozole treatment did not sex-specifically alter the expression levels of AROM [females: $0.34 \pm 0.10$ (vehicle) vs $0.41 \pm 0.08$ (letrozole); $p=0.66$; males: $0.41 \pm 0.09$ (vehicle) vs $0.44 \pm 0.09$ (letrozole); $p=0.82 ; n=6$ of each sex and treatment, Fig. 4O], $\mathrm{ER} \alpha$ [females: $0.66 \pm 0.10$ (vehicle) vs $0.64 \pm 0.09$ (letrozole); $p=0.87$; males: $0.51 \pm 0.09$ (vehicle) vs $0.52 \pm 0.12$ (letrozole); $p=0.96 ; n=7$ of each sex and treatment, Fig. $4 P]$, or AR [females: $0.41 \pm 0.05$ (vehicle) vs $0.49 \pm 0.09$ (letrozole); $p=0.44$; males: $0.54 \pm 0.09$ (vehicle) vs $0.58 \pm 0.09$ (letrozole); $p=0.74$; $n=8$ of each sex and treatment, Fig. 4Q], rendering it unlikely that a sex-specifically altered expression of these proteins underlies the sex-dependent plasticity in BLA.

\section{Letrozole affects synaptic transmission in the BLA sex-specifically}

We next questioned whether AROM inhibition also affects synaptic transmission in BLA sex-specifically. Because the most abundant expression of AROM was observed in the BL (Fig. 2), we stimulated the La and recorded fEPSPs in the BL in acute slices from naïve prepubertal rats (P20-P27), to which letrozole was supplied via the ACSF. In untreated control slices, HFS resulted in a significant potentiation $\left(F_{(1,12)}=21.2 ; p=0.001\right)$ of average fEPSP slopes both in female and male BL (Fig. $5 A, B$ ). These findings are in accordance with the data from the study by Krezel 
A

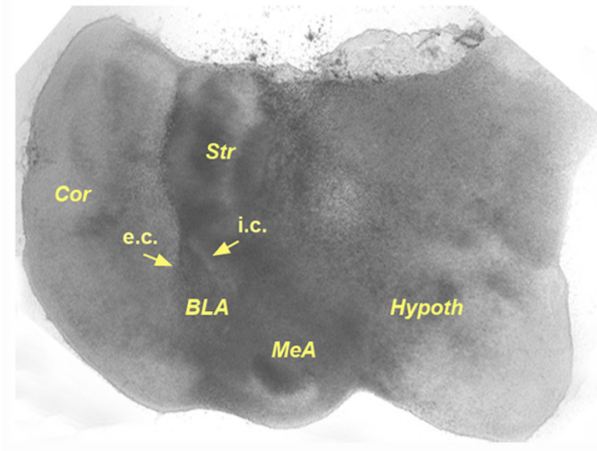

B

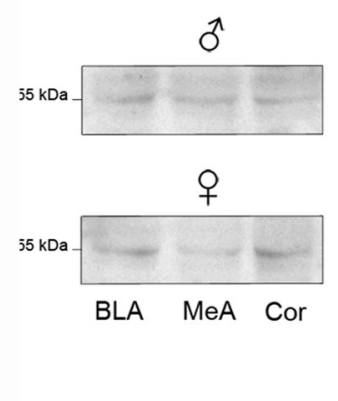

C

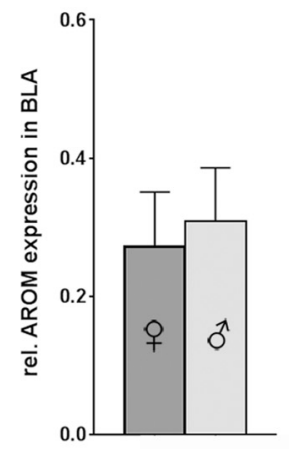

D

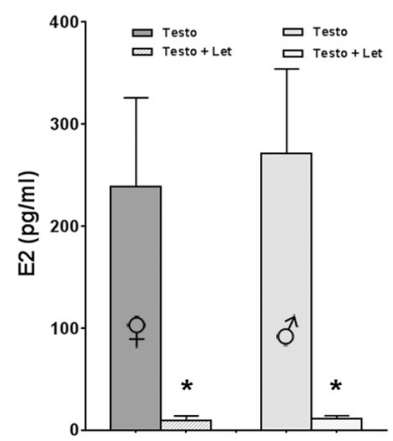

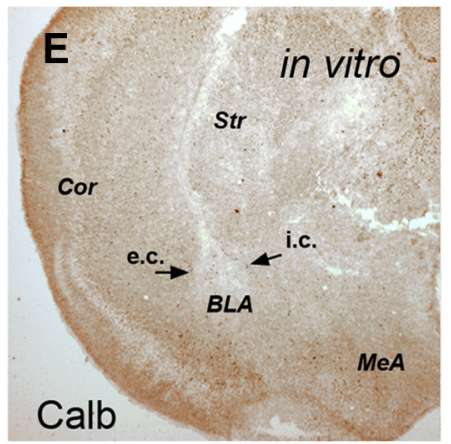
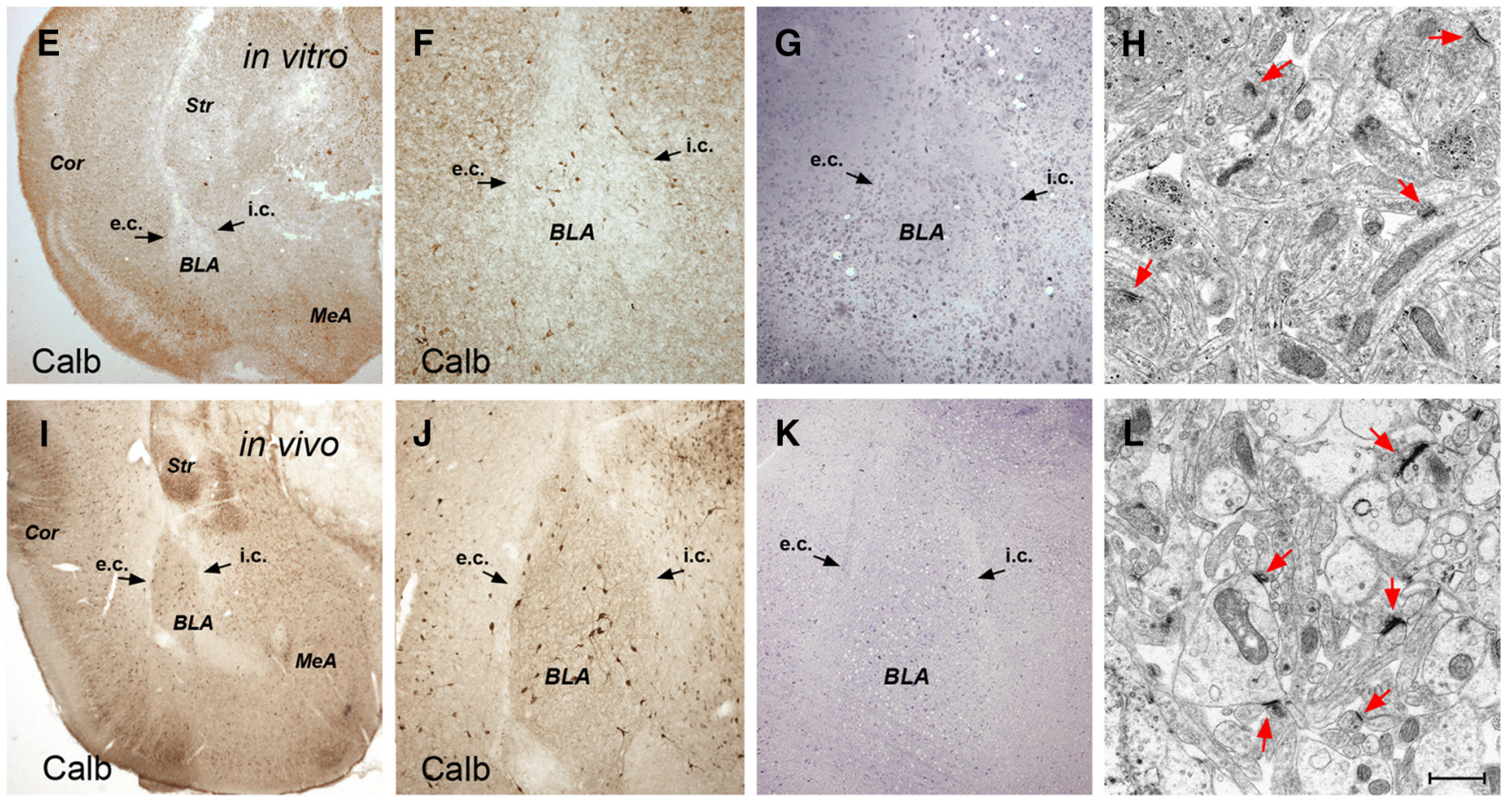

M

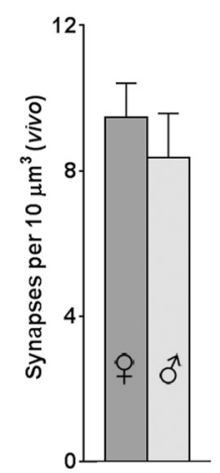

N

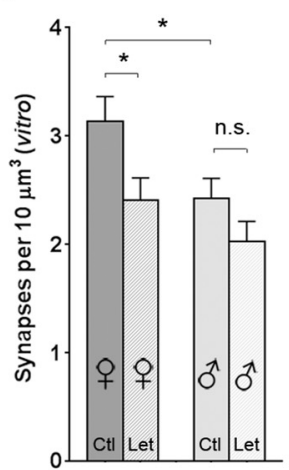

0

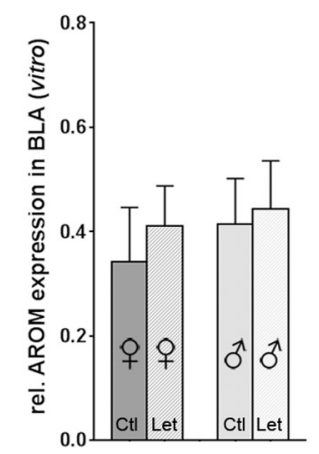

P

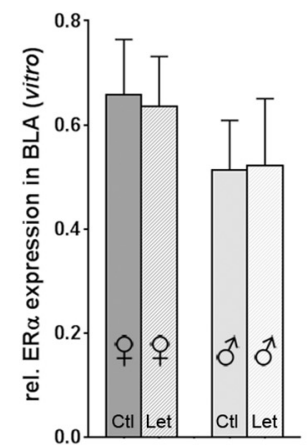

Q

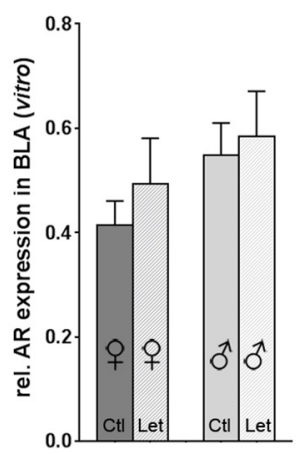

Figure 4. Reduced spine synapse density in BL of corticoamygdalar slice cultures from neonatal rats. $\boldsymbol{A}$, Representative organotypic corticoamygdalar slice culture after DIV14 [note: subdivisions of the amygdala, such as the BLA, which is embedded between the external capsule (e.c.) and intermediate capsule (i.c.), are identifiable (arrows)]. In addition to the amygdala and cortex (Cor), parts of the striatum (Str) and hypothalamus (Hypothal) have remained attached. B, C, AROM is expressed in the BLA of these cultures, and expression levels are similar to those detected in the MeA and adjacent Cor. No difference of AROM expression in BLA was evident between cultures deriving from males ( $\boldsymbol{B}$, top trace) and females ( $\boldsymbol{B}$, bottom trace; quantification in $\boldsymbol{C} ; n=9$, each sex). $\boldsymbol{D}$, AROM is functional in vitro, as testosterone (Testo; $10^{-7} \mathrm{M}$ ) supplemented to the culture medium was readily converted to E2 in cultures both from females ( $\left.239 \pm 87 \mathrm{pg} / \mathrm{ml}\right)$ and males $(271 \pm 83 \mathrm{pg} / \mathrm{ml}$ ). Coapplication of letrozole (Let; $10^{-7} \mathrm{M}$ ) caused a drastic reduction of testosterone conversion to $\mathrm{E} 2$ in cultures from both sexes, demonstrating efficient AROM inhibition. No difference between the sexes was evident (Testo + Let, $10 \pm 4 \mathrm{pg} / \mathrm{ml}$ in cultures from females; $p=0.04$, if compared with Testo; $11 \pm 3 \mathrm{pg} / \mathrm{ml}$ in cultures from males, $p=0.02 ; n=4$, for each experimental treatment and sex). $\boldsymbol{E}-\boldsymbol{L}$, Comparison of a DIV14 organotypic culture (in vitro, $\boldsymbol{E}-\boldsymbol{H}$ ) and an age-equivalent (P17) rat (in vivo, $\boldsymbol{I}-\boldsymbol{L}): \boldsymbol{E}, \boldsymbol{F}, \boldsymbol{I}, \boldsymbol{J}$, , The expression pattern of the interneuron marker $\mathrm{Calb}$ in vitro $(\boldsymbol{E}, \boldsymbol{F})$ replicates the pattern in vivo $(\boldsymbol{I}, \boldsymbol{J})$. However, the numbers of Calb-expressing neurons in BLA are lower in the cultures, the somata are smaller, and neurites appear (Figure legend continues.) 

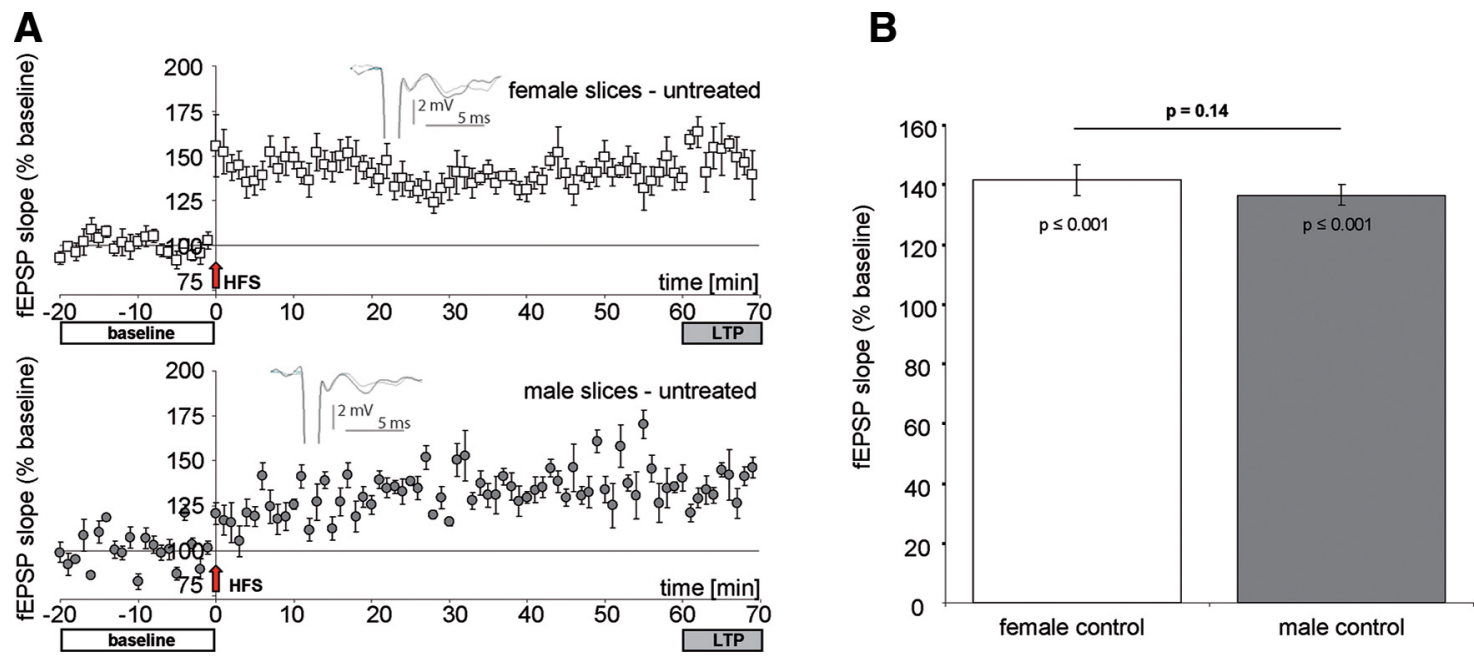

Figure 5. Induction of LTP in BL of juvenile female and male rats. A, Averaged fEPSP slopes (percentage of baseline) under control conditions in amygdala slices from female (top) and male (bottom) rats before and after HFS. Insets show characteristic fEPSPs of recordings $10 \mathrm{~min}$ before (gray) and $60 \mathrm{~min}$ after HFS (black). B, Synaptic potentiation was significantly increased after HFS $\left(F_{(1,12)}=21.2, p=0.001\right.$, mixed-factor ANOVA $)$ in amygdala slices from both sexes, up to $141.6 \pm 5.1 \%(n=8, N=6)$ in females and up to $136.5 \pm 3.5 \%(n=6, N=6)$ in males. No significant difference was found in a raw data comparison between both sexes $\left(F_{(1,12)}=4.4, p=0.11\right.$, mixed-factor ANOVA; Brown-Forsythe test $\left.p=0.14\right)$.

et al. (2001), who performed similar recordings in mice. In control slices, we found no significant difference in synaptic potentiation 60 min after HFS between the sexes $\left(F_{(1,12)}=4.4 ; p=0.11\right.$; Brown-Forsythe test, $p=0.14)$. However, if letrozole was applied, male and female slices responded differently (Fig. 6A-C), as follows: in slices from females, 60 min of letrozole virtually abolished the induction of LTP by HFS without affecting baseline synaptic transmission (Fig. 6A). In contrast, in slices from males (Fig. 6B), letrozole slowly increased baseline synaptic responses to $135 \pm 9 \%$ of baseline, and HFS subsequently further increased average fEPSP slopes to $156 \pm 10 \%$ of baseline. Statistical analysis using mixed-factor ANOVA revealed a highly significant difference with respect to the "within-subject factor" (fEPSP slope after HFS; $\left.F_{(2,24)}=9.7 ; p \leq 0.001\right)$, but not with respect to the "between-subject factor" (males vs females; $F_{(1,12)}=1.5 ; p=$ 0.244 ). Because mixed-factor ANOVA may not sufficiently discriminate between the putative letrozole effects in the two sexes,

$\leftarrow$

(Figure legend continued.) less developed, suggesting that differentiation in the cultures is impaired ( $\boldsymbol{F}$ and $\boldsymbol{J}$ are higher magnifications of $\boldsymbol{E}$ and $\boldsymbol{I}$, respectively). $\boldsymbol{G}, \boldsymbol{K}$, Semithin sections showing that BLA is identifiable in vitro $(\boldsymbol{G})$, as remnants of the external capsule (e.c.) and intermediate capsule (i.c.) are preserved ( $\boldsymbol{G}, \boldsymbol{K}$, arrows). $\boldsymbol{H}, \boldsymbol{L}$, Spine synapses (red arrows) are formed in the BLA in vitro $(\boldsymbol{H})$, but synapse density is lower in the culture than in a section from a P17 rat $(\boldsymbol{L}) \cdot \boldsymbol{M}, \boldsymbol{N}$, Quantitative analyses of spine synapse density in the BLA of P17 rats $(\boldsymbol{M})$ and of DIV14 corticoamygdalar cultures $(\boldsymbol{N})$, which have been incubated for $7 \mathrm{~d}$ (DIV7 $\rightarrow$ DIV14) with either letrozole $\left(10^{-7} \mathrm{M}\right.$ ) or vehicle (DMSO) Note that, as in adult mice, letrozole caused a significant reduction of spine synapse density in BLA in the cultures from females (vehicle, $3.1 \pm 0.2$ synapses $/ 10 \mu \mathrm{m}^{3}$; Let, $2.4 \pm 0.2$ synapses $/ 10 \mu \mathrm{m}^{3} ; p=0.02 ; n=15$ cultures in each group), but not from males (vehicle, $2.4 \pm 0.2$ synapses $/ 10 \mu \mathrm{m}^{3}$; Let, $2.0 \pm 0.2$ synapses $/ 10 \mu \mathrm{m}^{3} ; p=0.14 ; n=11$ cultures in each group). Further, as in the adult mice, spine synapse density was significantly lower in the male compared with female BLA under control conditions $(p=0.03)$. Spine synapse densities in the BLA of age-equivalent (P17) rats $(\boldsymbol{M})$ were markedly (approximately threefold) higher than in the cultures, suggesting reduced extrinsic or intrinsic connectivity in vitro. Densities were somewhat lower in males $(8.4 \pm 1.2$ synapses $\left./ 10 \mu \mathrm{m}^{3} ; n=4\right)$ compared with females $\left(9.5 \pm 0.9\right.$ synapses $\left./ 10 \mu \mathrm{m}^{3} ; n=4\right)$, but this difference was not significant $(p=0.4) . \mathbf{0}-\mathbf{Q}$, Western blot analyses determining the effect of a $7 \mathrm{~d}$ letrozole treatment on the expression of $\operatorname{AROM}(\mathbf{0}), \operatorname{ER} \alpha(\boldsymbol{P})$, and $A R(\boldsymbol{Q})$ in BLA in vitro. Note that in cultures from both females and males, letrozole treatment did not significantly alter expression levels of these proteins (see main text for quantitative details). Scale bar (in $\boldsymbol{L}): A, E, I, 500 \mu \mathrm{m} ; \boldsymbol{F}, \boldsymbol{G}, \boldsymbol{J}, \boldsymbol{K}, 100 \mu \mathrm{m} ; \boldsymbol{H}, \boldsymbol{L}, 1 \mu \mathrm{m}$. we additionally applied one-way ANOVA, which revealed a significant increase of fEPSP slope after letrozole wash-in and HFS in the slices from males $\left(F_{(2,23)}=4.8 ; p=0.019\right.$; Fig. $\left.6 D\right)$ but not in those from females $\left(F_{(2,17)}=0.26 ; p=0.78\right.$; Fig. $\left.6 D\right)$. These findings highlight that letrozole had prevented synaptic potentiation in the females but not in the males.

\section{Similar expression of ER $\alpha$ and ARs in the BLA of male and female rats}

The sex-specific response to AROM inhibition, as described above, could reflect differences in the expression of estrogen or androgen receptors in the BLA of juvenile male versus female rats. In addition to analyses in vitro (Figs. $4 P, Q$ ), we therefore examined whether such differences are evident in vivo, using immunohistochemistry and Western blot analysis: ER $\alpha$, the predominant estrogen receptor in the BLA (Shughrue et al., 1997; Osterlund et al., 1998), was abundantly expressed in the BLA, $\mathrm{CeA}$, and MeA both in males and females (Fig. 7A-C), but expression levels in BLA did not differ between the sexes (rel. expression of ER $\alpha: 0.45 \pm 0.05$ in females vs $0.48 \pm 0.09$ in males; $p=0.77 ; n=8$ of each sex; Fig. $7 D$ ), arguing against a regulation of the observed effects in the juvenile rats via sex-dependent ER $\alpha$ expression. Because the inhibition of AROM will cause testosterone levels to increase (Harden and MacLusky, 2005; Simpson et al., 2005), we further performed the same analysis for ARs. In contrast to $\mathrm{ER} \alpha$, AR expression was markedly lower in BLA, if compared with CeA and MeA (Fig. 7E-G), and AR immunoreactivity in BLA was distinct (Fig. $7 E, F$, insets), suggesting that ARs could be localized to specific neuronal populations. However, expression levels of ARs in BLA also did not differ significantly between males and females (rel. expression of AR: $0.50 \pm$ 0.06 in females vs $0.43 \pm 0.11$ in males; $p=0.58 ; n=8$ of each sex; Fig. $7 H)$.

\section{Discussion}

It has been known for some time that the E2-synthesizing enzyme AROM is expressed in the brain (Naftolin and MacLusky, 1982). Particularly high levels of AROM activity have been detected in brain regions associated with reproductive neuroendocrine functions, such as the medial basal hypothalamus, the bed nucleus of 

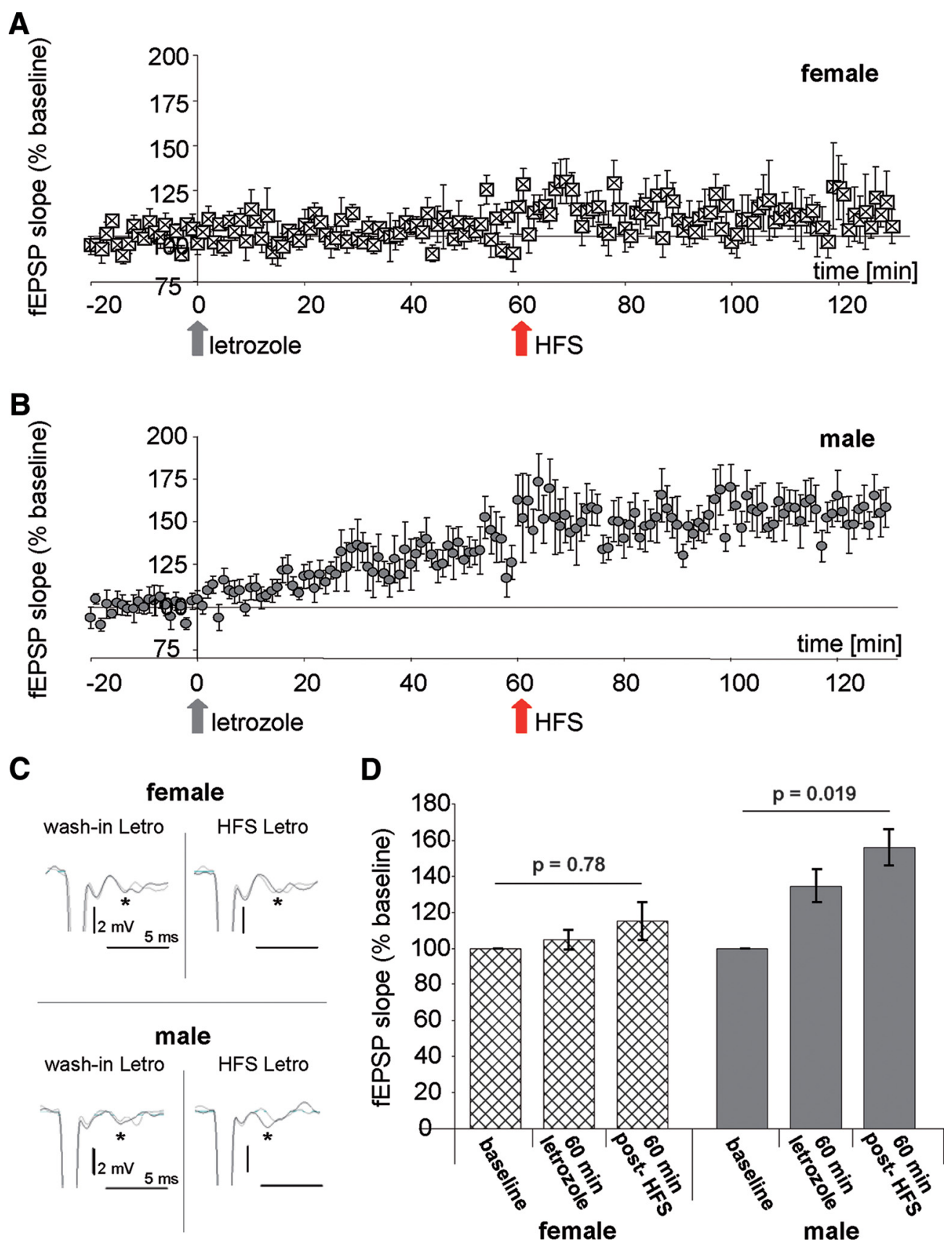

Figure 6. Aromatase inhibition prevents LTP in the BL of female rats, but not in male rats. $A, B$, Averaged fEPSP slopes (percentage of baseline) before letrozole wash-in (baseline), after letrozole wash-in (gray arrow), and after HFS in letrozole (red arrow) in amygdale slices from female $(\boldsymbol{A})$ and male (B) rats. C, Characteristic fEPSPs slopes (asterisks) in females (top) and males (bottom); left, $10 \mathrm{~min}$ before letrozole wash-in (gray) and $60 \mathrm{~min}$ after letrozole wash-in (black); right, $60 \mathrm{~min}$ before (gray) and after HFS in letrozole (black). $D$, Quantitative analysis of the data from experiments shown in $\boldsymbol{A}$ and $\boldsymbol{B}$ : mixed-factor ANOVA reveals no significant differences between females and males $\left(F_{(1,12)}=1.5 ; p=0.244\right)$ but indicates significant differences when letrozole and HFS were applied $\left(F_{(2,24)}=9.7 ; p \leq 0.001\right)$. For further differentiation one-way ANOVA was applied, demonstrating significant changes in fEPSP slopes before letrozole treatment, 60 min after letrozole treatment, and $60 \mathrm{~min}$ after HFS in the presence of letrozole in males $\left(100 \pm 1.3 \%, 134.7 \pm 9 \%, 156.1 \pm 10 \% ; F_{(2,23)}=4.8 ; p=0.019 ; n=8, N=8\right)$, but not in females $(100 \pm 2.3 \%, 104.9 \pm$ $\left.5.2 \%, 115 \pm 1.1 \% ; F_{(2,17)}=0.26 ; p=0.78 ; n=6, N=6\right)$.

the stria terminalis, or the medial amygdala (Roselli and Resko, 1987). In addition, AROM expression has been reported in regions that are not directly involved in the regulation of reproductive behavior, such as the hippocampus (Wehrenberg et al., 2001; Hojo et al., 2004; Bender et al., 2010), the neocortex (MacLusky et al., 1994; Yague et al., 2006, 2008), and, as also shown here, the central and basolateral amygdala (Sanghera et al., 1991; Wagner and Morrell, 1996; Horvath et al., 1997; Roselli et al., 1998; Zhao et al., 2007). This suggests that the functions of AROM in the brain are not limited to reproduction, but extend to mood, affec- tive behaviors, and memory formation. Our data support this view by showing that AROM is substantially expressed in amygdalar nuclei that are crucial for several forms of emotion and emotional memory (Beyeler et al., 2016), as follows: the basolateral (specifically BL) and central (specifically CeAl) amygdalar nuclei. Focusing on the BL, we further show that AROM is involved in the regulation of synaptic plasticity, as spine synapse density and synaptic properties were altered in the BL, if AROMmediated E2 production was reduced by the nonsteroidal AROM inhibitor letrozole. However, the observed effects were highly 

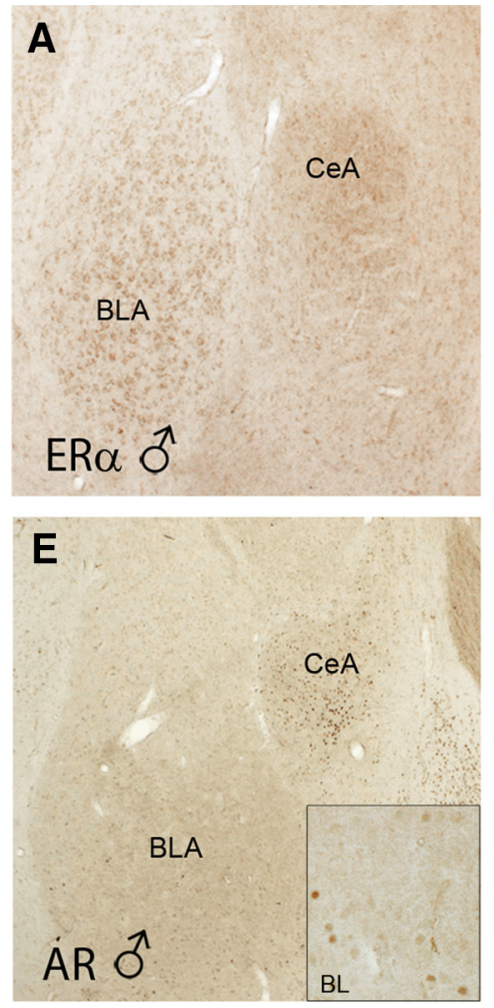
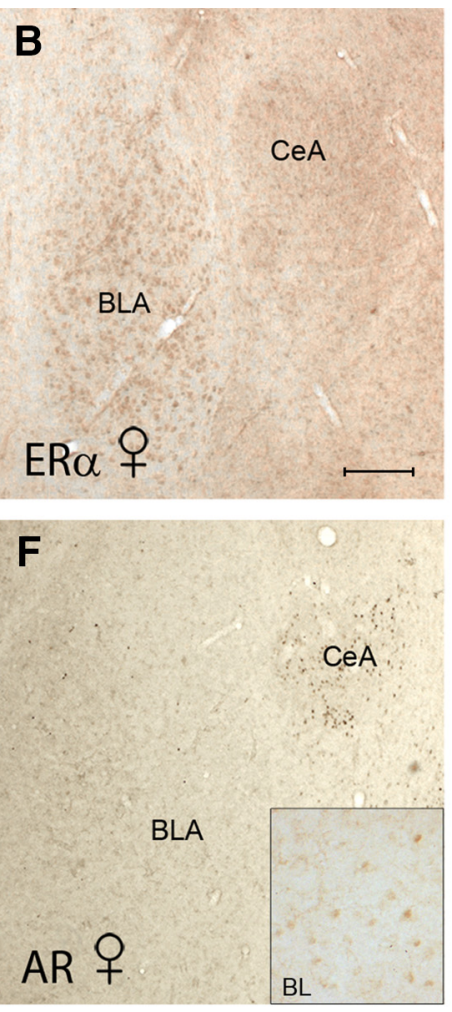
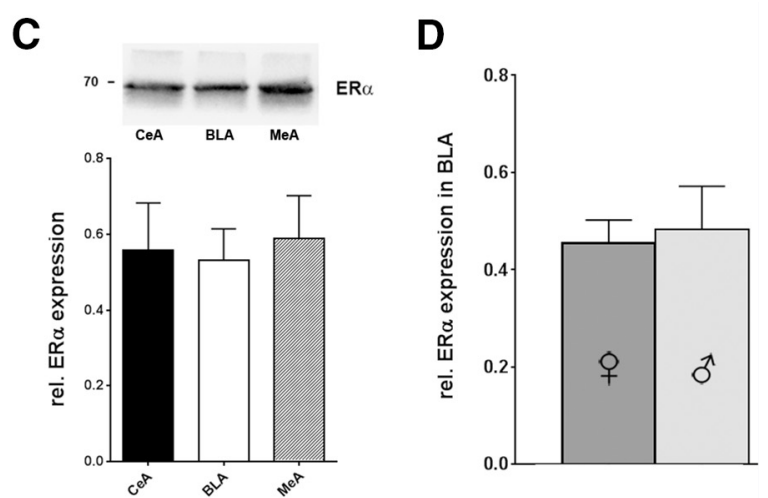

G

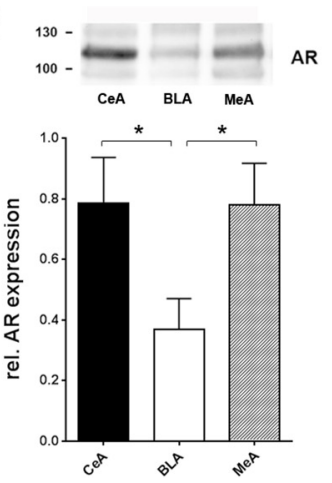

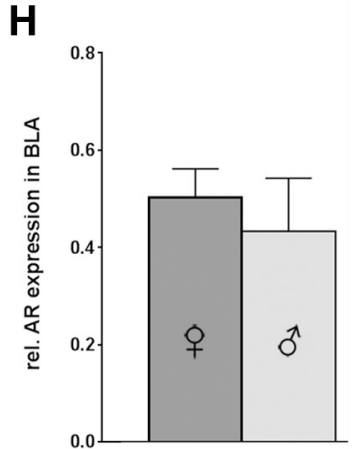

Figure 7. Expression of ER $\alpha$ s and ARs in rat BLA. $\boldsymbol{A}-\boldsymbol{D}$, Immunohistochemistry $(\boldsymbol{A}, \boldsymbol{B})$ and quantitative Western blot analyses $(\boldsymbol{C}, \boldsymbol{D})$ of ER $\alpha$ expression in the $B L A$, CeA, and MeA of juvenile male and female rats: expression was prominent in all subregions, but there was no expression difference between the subregions $(F=0.07, p=0.92$, one-way ANOVA; $n=6,3$ for each sex; $C$ and between the sexes in BLA (rel. expression of ER $\alpha$ : $0.45 \pm 0.05$ in females vs $0.48 \pm 0.09$ in males; $p=0.77$, unpaired $t$ test; $n=8$ of each sex; $D$ ) was evident. The top lane in $($ shows representative ER $\alpha$ bands in the BLA, CeA, and MeA. $\boldsymbol{E}-\boldsymbol{H}$, Immunohistochemistry $(\boldsymbol{E}, \boldsymbol{F})$ and quantitative Western blot analyses $(\boldsymbol{G}, \boldsymbol{H})$ of AR expression in the BLA, CeA, and MeA of juvenile male and female rats: stronger expression in the CeA and MeA compared with the $B L A(F=3.3, p=0.06$, one-way ANOVA; Bonferroni's multiple-comparison tests revealed significant differences for BLA vs MeA and BLA vs (eA; $p<0.05 ; n=6$ of each sex, $G$ ), but no expression differences between the sexes in BLA (rel. expression of AR: $0.50 \pm 0.06$ in females vs $0.43 \pm 0.11$ in males; $p=0.58$, unpaired $t$ test; $n=8$ of each sex; $\boldsymbol{H}$ ) were observed. The top lane in $\boldsymbol{G}$ shows representative AR bands in the BLA, (eA, and MeA. Insets, Higher-magnification views of BL show AR immunoreactivity, localizing to the nuclei of distinct cells. Scale bars: $A, B, E, F, 150 \mu \mathrm{m}$; insets, $40 \mu \mathrm{m}$.

sex-dependent; whereas, in the female BL, letrozole application caused a reduction of spine synapse density and virtually abolished LTP, spine synapses were unaltered, and synaptic potentiation was not suppressed by letrozole in the male BL.

Previously described sex differences involving AROM in brain areas related to reproductive behavior clearly result from sexdependent AROM expression levels, which are regulated by gonadal hormones (Abdelgadir et al., 1994; Zhao et al., 2007; Tabatadze et al., 2014). AROM expression levels in cortical structures including the basolateral amygdala, however, appear not to be governed by gonadal hormones (Tabatadze et al., 2014). Nevertheless, as shown in the present study, sex-specific differences in AROM function in the BLA exist. In adult mice, these differences could potentially be explained by fluctuations of peripheral E2 during the female estrous cycle (Woolley and McEwen, 1992), because, in our experiments, mice were not ovariectomized to avoid dysregulation of the hypothalamus-pituitary axis (PrangeKiel et al., 2008). However, consistent findings in neonatal corticoamygdalar cultures and in acute slices from prepubertal rats, in which the influence of peripheral E2 is excluded, do not support this interpretation. Our present findings are further concordant with previous observations in the hippocampus, in which the inhibition of aromatase significantly reduced spine synapse densities both in gonadally intact and in ovariectomized female, but not in male mice (Zhou et al., 2010; Vierk et al., 2012). In addition, letrozole reduced hippocampal LTP sex-specifically at doses that were also used in the present study (Vierk et al., 2015). To- gether, these data suggest that brain AROM has sex-specific functions that are independent of circulating E2 levels.

Our findings may thus be better explained by the assumption that a pre-existing sex difference in E2 signaling has become unmasked by the inhibition of an endogenous (amygdalar) E2 production via letrozole. As AROM produces E2 from testosterone, which otherwise would be converted by $5 \alpha$-reductase to dihydrotestosterone (DHT), the most potent androgen (Selmanoff et al., 1977), its inhibition will result in a shift in the levels of these hormones, reducing E2, and increasing testosterone and DHT (Harden and MacLusky, 2005; Simpson et al., 2005). Several lines of evidence suggest that androgens (specifically DHT) have a synaptogenic potential similar to that of estrogens (Hajszan et al., 2008). For instance, reduced hippocampal spine and spine synapse densities after ovariectomy are rescued by E2 in female rats (Gould et al., 1990), while DHT restores synapse loss in males after the removal of the testes (Leranth et al., 2003). Further, the application of testosterone or DHT to primary hippocampal neurons promotes a rapid, AR-dependent increase in spine density (Hatanaka et al., 2015), similar to that mediated by E2 via ER $\alpha$ (Mukai et al., 2007). An increase of androgens may thus be capable of replacing E2 after AROM inhibition, but may do this sexdependently, if male neurons are "programmed" to preferentially respond to androgens while female neurons preferentially respond to E2 (Hajszan et al., 2008). Indeed, sex-specific "programming" of neurons has been described. For instance, the exposure of neonatal hippocampal and striatal neurons to E2 or 
testosterone alters their responsiveness to estradiol throughout life via sex-specific priming of estrogen receptor-mediated signaling pathways (Meitzen et al., 2012, 2013), demonstrating that sexual hormones promote a sex-specific organization of brain tissue on the molecular level during certain developmental phases (McCarthy and Arnold, 2011; Chung and Auger, 2013). Along this line, a developmentally primed, sex-specific E2 modulation of mGluR signaling was recently reported (Boulware et al., 2005; Huang and Woolley, 2012; Tabatadze et al., 2015). We therefore regard it as reasonable that a developmental sex-specific priming of signaling pathways also underlies the sex difference in the $\mathrm{BL}$, which is established already neonatally (Fig. 4). ER $\alpha$ mediated signaling is a likely candidate for priming (Tabatadze et al., 2015), as $\mathrm{ER} \alpha$ is considered to be the predominant estrogen receptor in BLA (Shughrue et al., 1997; Osterlund et al., 1998). However, a role of ER $\beta$ cannot be excluded, particularly in the light of findings that LTP is altered in the BLA of female but not male ER $\beta$-deficient mice, although these effects could also reflect ER $\beta$ functions outside of the BLA (Krezel et al., 2001).

A preference of male neurons for androgens and female neurons for estrogens could further explain our observation that letrozole wash-in alone (without HFS) already increased synaptic transmission in male BL, whereas it had no effect in female BL (Fig. 6D). Arguing against this interpretation are observations that the physiological effects of androgens (specifically DHT) appear to be inhibitory rather than excitatory (Reddy, 2004; Di Mauro et al., 2015). It must be considered, however, that androgen effects depend on the localization of the receptors, which appears to be highly distinct in the BL (Fig. $7 E, F$ ). A selective expression of ARs (e.g., on inhibitory neurons) could thus cause AR-mediated effects in the BL to differ from those previously observed in the hippocampus (Di Mauro et al., 2015). An alternative explanation may arise from recent observations that E2 suppresses perisomatic inhibition of CA1 pyramidal cells in female but not male rat hippocampus via a mechanism that promotes ER $\alpha$-mGluR1 association and involves sex-specific endocannaboid signaling (Huang and Woolley, 2012; Tabatadze et al., 2015). If these mechanisms were also active in the BL, the withdrawal of endogenous E2 would result in increased inhibition in the females (abolishing LTP), but not in the males, in which increased excitation could be the net effect. Clearly, additional studies will be necessary to determine whether any of these scenarios underlies the observed effects.

Finally, our findings underline the necessity to study both sexes if one wants to fully understand the mechanisms of fear and anxiety, because sex differences in hormonal signaling could manifest as sex differences in associative learning and emotional responding. Substantial evidence for such differences exists, as follows: the prevalence of anxiety disorders is twice as high in women (Kinrys and Wygant, 2005), and men and women differ in their ability to extinguish fear (Milad et al., 2009; Zeidan et al., 2011). Likewise, classic conditioning upon stressful stimuli differs between male and female rats, depending on estrogen levels (Wood and Shors, 1998). While previous studies have mainly attributed these differences to varying peripheral hormone levels, particularly during the female estrous cycle, the novelty of our findings is that these differences do not have to be caused by the peripheral hormones, but could be mediated by neurosteroids intrinsically synthesized by the amygdala. As AROM is regulated by neuronal activity (Balthazart and Ball, 2006; Charlier et al., 2015; Fester et al., 2016) and is subject to endocrine regulation (Prange-Kiel et al., 2008), it is well positioned to integrate signals from both the neuroendocrine (hormonal) and neuronal (activity-dependent) environment, and thus to modulate synaptic activity accordingly. This could be particularly important in BLA, which coordinates subcortical input (Asan et al., 2013) with sensory input from the thalamus and somatosensory cortex (Pitkänen et al., 1997), and is reciprocally connected with the ventral hippocampus and medial prefrontal cortex (Seidenbecher et al., 2003; Hoover and Vertes, 2007; Orsini et al., 2011; Felix-Ortiz et al., 2013). Examining E2-mediated synaptic plasticity in the BLA and CeA in more detail may thus help to better understand certain sex differences in mood disorders as well as certain side effects of AROM inhibitors, which are frequently used for breast cancer therapy (Gallicchio et al., 2012).

\section{References}

Abdelgadir SE, Resko JA, Ojeda SR, Lephart ED, McPhaul MJ, Roselli CE (1994) Androgens regulate aromatase cytochrome P450 messenger ribonucleic acid in rat brain. Endocrinology 135:395-401. CrossRef Medline

Arevalo MA, Azcoitia I, Gonzalez-Burgos I, Garcia-Segura LM (2015) Signaling mechanisms mediating the regulation of synaptic plasticity and memory by estradiol. Horm Behav 74:19-27. CrossRef Medline

Asan E, Steinke M, Lesch KP (2013) Serotonergic innervation of the amygdala: targets, receptors and implications for stress and anxiety. Histochem Cell Biol 139:785-813. CrossRef Medline

Balthazart J, Ball GF (2006) Is brain estradiol a hormone or a neurotransmitter? Trends Neurosci 29:241-249. CrossRef Medline

Balthazart J, Foidart A, Surlemont C, Harada N (1991) Distribution of aromatase-immunoreactive cells in the mouse forebrain. Cell Tissue Res 263:71-79. CrossRef Medline

Bayer J, Rune G, Schultz H, Tobia MJ, Mebes I, Katzler O, Sommer T (2015) The effect of estrogen synthesis inhibition on hippocampal memory. Psychoneuroendocrinology 56:213-225. CrossRef Medline

Bender RA, Zhou L, Wilkars W, Fester L, Lanowski JS, Paysen D, König A, Rune GM (2010) Roles of $17 \beta$-estradiol involve regulation of reelin expression and synaptogenesis in the dentate gyrus. Cereb Cortex 20:29852995. CrossRef Medline

Beyeler A, Namburi P, Glober GF, Simonnet C, Calhoon GG, Conyers GF, Luck R, Wildes CP, Tye KM (2016) Divergent routing of positive and negative information from the amygdala during memory retrieval. Neuron 90:348-361. CrossRef Medline

Boulware MI, Weick JP, Becklund BR, Kuo SP, Groth RD, Mermelstein PG (2005) Estradiol activates group I and II metabotropic glutamate receptor signaling, leading to opposing influences on cAMP response elementbinding protein. J Neurosci 25:5066-5078. CrossRef Medline

Charlier TD, Cornil CA, Patte-Mensah C, Meyer L, Mensah-Nyagan AG, Balthazart J (2015) Local modulation of steroid action: rapid control of enzymatic activity. Front Neurosci 9:83. CrossRef Medline

Chung WC, Auger AP (2013) Gender differences in neurodevelopment and epigenetics. Pflugers Arch 465:573-584. CrossRef Medline

Di Mauro M, Tozzi A, Calabresi P, Pettorossi VE, Grassi S (2015) Neosynthesis of estrogenic or androgenic neurosteroids determine whether long-term potentiation or depression is induced in hippocampus of male rat. Front Cell Neurosci 9:376. CrossRef Medline

Dowsett M, Folkerd E, Doody D, Haynes B (2005) The biology of steroid hormones and endocrine treatment of breast cancer. Breast 14:452-457. CrossRef Medline

Drakew A, Frotscher M, Heimrich B (1999) Blockade of neuronal activity alters spine maturation of dentate granule cells but not their dendritic arborization. Neuroscience 94:767-774. CrossRef Medline

Felix-Ortiz AC, Beyeler A, Seo C, Leppla CA, Wildes CP, Tye KM (2013) BLA to vHPC inputs modulate anxiety-related behaviors. Neuron 79: 658-664. CrossRef Medline

Fester L, Prange-Kiel J, Jarry H, Rune GM (2011) Estrogen synthesis in the hippocampus. Cell Tissue Res 345:285-294. CrossRef Medline

Fester L, Brandt N, Windhorst S, Pröls F, Bläute C, Rune GM (2016) Control of aromatase in hippocampal neurons. J Steroid Biochem Mol Biol 160:9-14. CrossRef Medline

Gallicchio L, MacDonald R, Wood B, Rushovich E, Helzlsouer KJ (2012) Menopausal-type symptoms among breast cancer patients on aromatase inhibitor therapy. Climacteric 15:339-349. CrossRef Medline

Gould E, Woolley CS, Frankfurt M, McEwen BS (1990) Gonadal steroids 
regulate dendritic spine density in hippocampal pyramidal cells in adulthood. J Neurosci 10:1286-1291. Medline

Grassi S, Frondaroli A, Scarduzio M, Dutia MB, Dieni C, Pettorossi VE (2010) Neural 17beta-estradiol facilitates long-term-potentiation in the hippocampal CA1 Region. Neuroscience 165:1100-1114. CrossRef Medline

Hajszan T, MacLusky NJ, Leranth C (2008) Role of androgens and the androgen receptor in remodeling of spine synapses in limbic brain areas. Horm Behav 53:638-646. CrossRef Medline

Harden C, MacLusky NJ (2005) Aromatase inhibitors as add-on treatment for men with epilepsy. Expert Rev Neurother 5:123-127. CrossRef Medline

Hatanaka Y, Hojo Y, Mukai H, Murakami G, Komatsuzaki Y, Kim J, Ikeda M, Hiragushi A, Kimoto T, Kawato S (2015) Rapid increase of spines by dihydrotestosterone and testosterone in hippocampal neurons: dependence on synaptic androgen receptor and kinase networks. Brain Res 1621:121-132. CrossRef Medline

Hojo Y, Hattori TA, Enami T, Furukawa A, Suzuki K, Ishii HT, Mukai H, Morrison JH, Janssen WG, Kominami S, Harada N, Kimoto T, Kawato S (2004) Adult male rat hippocampus synthesizes estradiol from pregnenolone by cytochromes P45017alpha and P450 aromatase localized in neurons. Proc Natl Acad Sci U S A 101:865-870. CrossRef Medline

Hojo Y, Murakami G, Mukai H, Higo S, Hatanaka Y, Ogiue-Ikeda M, Ishii H, Kimoto T, Kawato S (2008) Estrogen synthesis in the brain-role in synaptic plasticity and memory. Mol Cell Endocrinol 290:31-43. CrossRef Medline

Hoover WB, Vertes RP (2007) Anatomical analysis of afferent projections to the medial prefrontal cortex in the rat. Brain Struct Funct 212:149-179. CrossRef Medline

Horvath TL, Roa-Pena L, Jakab RL, Simpson ER, Naftolin F (1997) Aromatase in axonal processes of early postnatal hypothalamic and limbic areas including the cingulate cortex. J Steroid Biochem Mol Biol 61:349-357. CrossRef Medline

Huang GZ, Woolley CS (2012) Estradiol acutely suppresses inhibition in the hippocampus through a sex-specific endocannaboid and mGluRdependent mechanism. Neuron 74:801-808. CrossRef Medline

Kato A, Hojo Y, Higo S, Komatsuzaki Y, Murakami G, Yoshino H, Uebayashi M, Kawato S (2013) Female hippocampal estrogens have a significant correlation with cyclic fluctuation of hippocampal spines. Front Neural Circuits 7:149. CrossRef Medline

Kemppainen S, Pitkänen A (2000) Distribution of parvalbumin, calretinin, and calbindin- $\mathrm{D}(28 \mathrm{k})$ immunoreactivity in the rat amygdaloid complex and colocalization with gamma-aminobutyric acid. J Comp Neurol 426: 441-467. CrossRef Medline

Kinrys G, Wygant LE (2005) Anticonvulsants in anxiety disorders. Curr Psychiatry Rep 7:258-267. CrossRef Medline

Korol DL, Pisani SL (2015) Estrogens and cognition: friends and foes? An evaluation of the opposing effects of estrogens on learning and memory. Horm Behav 74:105-115. CrossRef Medline

Kretz O, Fester L, Wehrenberg U, Zhou L, Brauckmann S, Zhao S, PrangeKiel J, Naumann T, Jarry H, Frotscher M, Rune GM (2004) Hippocampal synapses depend on hippocampal estrogen synthesis. J Neurosci 24: 5913-5921. CrossRef Medline

Krezel W, Dupont S, Krust A, Chambon P, Chapman PF (2001) Increased anxiety and synaptic plasticity in estrogen receptor $\beta$-deficient mice. Proc Natl Acad Sci U S A 98:12278-12282. CrossRef Medline

LeDoux J (2007) The amygdala. Curr Biol 17:R868-R874. CrossRef Medline

Leranth C, Petnehazy O, MacLusky NJ (2003) Gonadal hormones affect spine synaptic density in the CA1 hippocampal subfield of male rats. J Neurosci 23:1588-1592. Medline

MacLusky NJ, Walters MJ, Clark AS, Toran-Allerand CD (1994) Aromatase in the cerebral cortex, hippocampus, and mid-brain: ontogeny and developmental implications. Mol Cell Neurosci 5:691-698. CrossRef Medline

McCarthy MM, Arnold AP (2011) Reframing sexual differentiation of the brain. Nat Neurosci 14:677-683. CrossRef Medline

McDonald AJ (1992) Projection neurons of the basolateral amygdala: a correlative Golgi and retrograde tract tracing study. Brain Res Bull 28:179185. CrossRef Medline

McDonald AJ, Muller JF, Mascagni F (2002) GABAergic innervation of alpha type II calcium/calmodulin-dependent protein kinase immunoreac- tive pyramidal neurons in the rat basolateral amygdala. J Comp Neurol 446:199-218. CrossRef Medline

Meitzen J, Grove DD, Mermelstein PG (2012) The organizational and aromatization hypotheses apply to rapid estradiol action in female hippocampal neurons. Endocrinology 153:4616-4621. CrossRef Medline

Meitzen J, Perry AN, Westenbroek C, Hedges VL, Becker JB, Mermelstein PG (2013) Enhanced striatal $\beta 1$-adrenergic receptor expression following hormone loss in adulthood is programmed by both early sexual differentiation and puberty: a study of humans and rats. Endocrinology 154: 1820-1831. CrossRef Medline

Milad MR, Pitman RK, Ellis CB, Gold AL, Shin LM, Lasko NB, Zeidan MA, Handwerger K, Orr SP, Rauch SL (2009) Neurobiological basis of failure to recall extinction memory in posttraumatic stress disorder. Biol Psychiatry 66:1075-1082. CrossRef Medline

Mukai H, Tsurugizawa T, Murakami G, Kominami S, Ishii H, Ogiue-Ikeda M, Takata N, Tanabe N, Furukawa A, Hojo Y, Ooishi Y, Morrison JH, Janssen WG, Rose JA, Chambon P, Kato S, Izumi S, Yamazaki T, Kimoto T, Kawato S (2007) Rapid modulation of long-term depression and spinogenesis via synaptic estrogen receptors in hippocampal principal neurons. J Neurochem 100:950-967. CrossRef Medline

Naftolin F, MacLusky NJ (1982) Aromatase in the central nervous system. Cancer Res 42 [8 Suppl]:3274s-3276s. CrossRef

Olucha-Bordonau FE, Fortes-Marco L, Otero-Garcia M, Lanuza E, MartinezGarcia F (2014) Amygdala: structure and function. In: The rat nervous system, Ed 4 (Paxinos G, ed), pp 441-489. San Diego, CA: Academic.

Orsini CA, Kim JH, Knapska E, Maren S (2011) Hippocampal and prefrontal projections to the basal amygdala mediate contextual regulation of fear after extinction. J Neurosci 31:17269-17277. CrossRef Medline

Osterlund M, Kuiper GG, Gustafsson JA, Hurd YL (1998) Differential distribution and regulation of estrogen receptor-alpha and -beta mRNA within the female rat brain. Mol Brain Res 54:175-180. CrossRef Medline

Pape HC, Pare D (2010) Plastic synaptic networks of the amygdala for the acquisition, expression, and extinction of conditioned fear. Physiol Rev 90:419-463. CrossRef Medline

Phillips KA, Ribi K, Fisher R (2011) Do aromatase inhibitors have adverse effects on cognitive function? Breast Cancer Res 13:203. CrossRef Medline

Pitkänen A, Savander V, LeDoux JE (1997) Organization of intra-amygdaloid circuitries in the rat: an emerging framework for understanding functions of the amygdala. Trends Neurosci 20:517-523. CrossRef Medline

Prange-Kiel J, Wehrenberg U, Jarry H, Rune GM (2003) Para/autocrine regulation of estrogen receptors in hippocampal neurons. Hippocampus 13:226-234. CrossRef Medline

Prange-Kiel J, Jarry H, Schoen M, Kohlmann P, Lohse C, Zhou L, Rune GM (2008) Gonadotropin-releasing hormone regulates spine density via its regulatory role in hippocampal estrogen synthesis. J Cell Biol 180:417426. CrossRef Medline

Puelles L, Kuwana E, Puelles E, Bulfone A, Shimamura K, Keleher J, Smiga S, Rubenstein JL (2000) Pallial and subpallial derivatives in the embryonic chick and mouse telencephalon, traced by the expression of the genes Dlx-2, Emx-1, Nkx-2.1, Pax-6, and Tbr-1. J Comp Neurol 424:409-438. CrossRef Medline

Reddy DS (2004) Testosterone modulation of seizure susceptibility is mediated by neurosteroids 3alpha-androstanediol and 17beta-estradiol. Neuroscience 129:195-207. CrossRef Medline

Roselli CE, Resko JA (1987) The distribution and regulation of aromatase activity in the central nervous system. Steroids 50:495-508. CrossRef Medline

Roselli CE, Abdelgadir SE, Rønnekleiv OK, Klosterman SA (1998) Anatomic distribution of aromatase gene expression in the rat brain. Biol Reprod 58:79-87. CrossRef Medline

Sanghera MK, Simpson ER, McPhaul MJ, Kozlowski G, Conley AJ, Lephart ED (1991) Immunocytochemical distribution of aromatase cytochrome P450 in the rat brain using peptide-generated polyclonal antibodies. Endocrinology 129:2834-2844. CrossRef Medline

Seidenbecher T, Laxmi TR, Stork O, Pape HC (2003) Amygdalar and hippocampal theta rhythm synchronization during fear memory retrieval. Science 301:846-850. CrossRef Medline

Selmanoff MK, Brodkin LD, Weiner RI, Siiteri PK (1977) Aromatization and $5 \alpha$-reduction of androgens in discrete hypothalamic and limbic regions of the male and female rat. Endocrinology 101:841-848. CrossRef Medline 
Shilling V, Jenkins V, Fallowfield L, Howell T (2003) The effects of hormone therapy on cognition in breast cancer. J Steroid Biochem Mol Biol 86:405412. CrossRef Medline

Shinoda K, Nagano M, Osawa Y (1994) Neuronal aromatase expression in preoptic, strial, and amygdaloid regions during late prenatal and early postnatal development in the rat. J Comp Neurol 343:113-129. CrossRef Medline

Shughrue PJ, Lane MV, Merchenthaler I (1997) Comparative distribution of estrogen receptor- $\alpha$ and $-\beta$ mRNA in the rat central nervous system. J Comp Neurol 388:507-525. CrossRef Medline

Simpson ER, Misso M, Hewitt KN, Hill RA, Boon WC, Jones ME, Kovacic A, Zhou J, Clyne CD (2005) Estrogen - the good, the bad, and the unexpected. Endocr Rev 26:322-330. CrossRef Medline

Smith Y, Paré JF, Paré D (1998) Cat intraamygdaloid inhibitory network: ultrastructural organization of parvalbumin-immunoreactive elements. J Comp Neurol 391:164-179. CrossRef Medline

Sterio DC (1984) The unbiased estimation of number and sizes of arbitrary particles using the disector. J Microsc 134:127-136. CrossRef Medline

Swanson LW, Petrovich GD (1998) What is the amygdala? Trends Neurosci 21:323-331. CrossRef Medline

Tabatadze N, Sato SM, Woolley CS (2014) Quantitative analysis of longform aromatase mRNA in the male and female rat brain. PLoS One 9:e100628. CrossRef Medline

Tabatadze N, Huang G, May RM, Jain A, Woolley CS (2015) Sex differences in molecular signaling at inhibitory synapses in the hippocampus. J Neurosci 35:11252-11265. CrossRef Medline

Tovote P, Fadok JP, Lüthi A (2015) Neuronal circuits for fear and anxiety. Nat Rev Neurosci 16:317-331. CrossRef Medline

Vierk R, Glassmeier G, Zhou L, Brandt N, Fester L, Dudzinski D, Wilkars W, Bender RA, Lewerenz M, Gloger S, Graser L, Schwarz J, Rune GM (2012) Aromatase inhibition abolishes LTP generation in female but not in male mice. J Neurosci 32:8116-8126. CrossRef Medline

Vierk R, Bayer J, Freitag S, Muhia M, Kutsche K, Wolbers T, Kneussel M, Sommer T, Rune GM (2015) Structure-function-behavior relationship in estrogen-induced synaptic plasticity. Horm Behav 74:139-148. CrossRef Medline
Wagner CK, Morrell JI (1996) Distribution and steroid hormone regulation of aromatase mRNA expression in the forebrain of adult male and female rats: a cellular-level analysis using in situ hybridization. J Comp Neurol 370:71-84. CrossRef Medline

Wehrenberg U, Prange-Kiel J, Rune GM (2001) Steroidogenic factor-1 expression in marmoset and rat hippocampus: co-localization with StAR and aromatase. J Neurochem 76:1879-1886. CrossRef Medline

Wood GE, Shors TJ (1998) Stress facilitates classical conditioning in males, but impairs classical conditioning in females through activational effects of ovarian hormones. Proc Natl Acad Sci U S A 95:4066-4071. CrossRef Medline

Woolley CS, McEwen BS (1992) Estradiol mediates fluctuation in hippocampal synapse density during the estrous cycle in the adult rat. J Neurosci 12:2549-2554. Medline

Yague JG, Muñoz A, de Monasterio-Schrader P, Defelipe J, Garcia-Segura LM, Azcoitia I (2006) Aromatase expression in the human temporal cortex. Neuroscience 138:389-401. CrossRef Medline

Yague JG, Wang AC, Janssen WG, Hof PR, Garcia-Segura LM, Azcoitia I, Morrison JH (2008) Aromatase distribution in the monkey temporal neocortex and hippocampus. Brain Res 1209:115-127. CrossRef Medline

Yuste R, Bonhoeffer T (2001) Morphological changes in dendritic spines associated with long-term synaptic plasticity. Annu Rev Neurosci 24: 1071-1089. CrossRef Medline

Zeidan MA, Igoe SA, Linnman C, Vitalo A, Levine JB, Klibanski A, Goldstein JM, Milad MR (2011) Estradiol modulates medial prefrontal cortex and amygdala activity during fear extinction in women and female rats. Biol Psychiatry 70:920-927. CrossRef Medline

Zhao C, Fujinaga R, Tanaka M, Yanai A, Nakahama K, Shinoda K (2007) Region-specific expression and sex-steroidal regulation on aromatase and its mRNA in the male rat brain: immunohistochemical and in situ hybridization analyses. J Comp Neurol 500:557-573. CrossRef Medline

Zhou L, Fester L, von Blittersdorff B, Hassu B, Nogens H, Prange-Kiel J, Jarry H, Wegscheider K, Rune GM (2010) Aromatase inhibitors induce spine synapse loss in the hippocampus of ovariectomized mice. Endocrinology 151:1153-1160. CrossRef Medline 